\title{
A Single-Stage Two-Switch PFC Rectifier with Wide Output Voltage Range and Automatic AC Ripple Power Decoupling
}

Abstract - Conventional single-phase power-factor-correction (PFC) rectifiers with active power decoupling capability typically require more than three active switches in their circuits. By exploring the concept of powerbuffer cell, a new single-stage PFC rectifier with two active switches, one inductor and one small powerbuffering capacitor is reported in this paper. The proposed converter can achieve high power factor, wide output voltage range, and power decoupling function without using electrolytic capacitor. Additionally, an automatic power decoupling control scheme which is simple and easy to implement is proposed in this paper. The operating principle, control method, and design considerations of the proposed rectifier are also provided. A $100 \mathrm{~W}$ prototype with $\mathrm{AC}$ input voltage of $110 \mathrm{Vrms}$ and a regulated DC output voltage ranging from $30 \mathrm{~V}$ to $100 \mathrm{~V}$ has been successfully designed and practically tested. The experimental results show that with only a 15 $\mu \mathrm{F}$ power-buffering film capacitor, the proposed converter can achieve an input power factor of over 0.98 , peak efficiency of $93.9 \%$, and output voltage ripple of less than $3 \%$, at $100 \mathrm{~W}$ output power.

\section{INTRODUCTION}

Single-phase power-factor-correction (PFC) rectifiers have been a preferred solution for a broad range of applications such as power supplies/chargers and lighting because of their circuit simplicity and low system cost. In offline AC to DC power conversion, ripple power of double-line frequency is injected from the AC source into the DC output [1]-[3]. Traditionally, large electrolytic capacitors (E-caps) are used at the DC output terminal for buffering the ripple power. However, an E-cap can take up a significant amount of the system volume (e.g. up to $80 \%$ in [4]) and can severely limit system's reliability [5]. Incorporation of active power decoupling control along with a slight modification of the rectifier has been found to be an effective approach that can significantly reduce the capacitance requirement necessary for power buffering [1], [4], [6]-[9]. With these solutions, ripple power can be diverted from the DC output into an external capacitor via 
an additional power decoupling circuit. Energy (E) stored in a capacitor $(C)$ is $E=0.5 \mathrm{CV}^{2}$. By allowing a large voltage (V) across the capacitor, only a small capacitor is required for storing a significant amount of ripple power [1]. Therefore, non-electrolytic capacitors (non-E-caps) with long lifetime (e.g. film capacitors, ceramic capacitors) can be used with the rectifier circuit in lieu of the E-caps.

The use of active power decoupling in rectifiers seems to work against the principle of system volume reduction. To simplify the circuit structure, several attempts based on circuit integration have been made (e.g. component sharing between a PFC rectifier and a power-decoupling circuit [7], [10]-[17]). Yet, a minimum of three active switches and two inductors are still needed with such solutions [7]. Some new advancement has been reported in [18], which describes a new 2-switch rectifier with active power decoupling capability. The rectifier is compact, reliable and cost-effective. The basic idea of this work is to introduce a type of series power buffer cell into the conventional buck PFC rectifier topology such that two extra operating states are created, i.e., a power charging state and a power discharging state [19], [20]. Power decoupling can therefore be easily achieved via controlling the duration of the two states. One major limitation of this rectifier, however, is that its output voltage range is limited to only half of the peak input voltage. Furthermore, the complementary control scheme used in this rectifier is based on an indirect form of open-loop control involving a complicated power-decoupling loop. In its control, the input AC current and output voltage are not directly regulated (they are not control variables). Instead, only the voltage of the power-buffering capacitor is directly controlled. The duty cycle commands are derived based on complicated open-loop calculations using measurements of the power-buffering capacitor voltage, the inductor current, the input voltage and the referenced (desired) output voltage information. Even with such complexity, however, the control is unable to provide accurate regulation of the output voltage and the instantaneous power stored by the power-buffering capacitors.

In this paper, the concept of series power buffer cell is further explored. By rotating the basic circuit cell in [18], a new type of two-switch buck-boost PFC rectifier is derived. This rectifier can achieve good PFC, 
output voltage regulation and power decoupling capabilities, all in a single stage. As compared to previous work presented in [18], the proposed rectifier has a new feature of having a wide output voltage range. Furthermore, a novel closed-loop control scheme that can directly regulate the input current and output voltage is proposed. It should be emphasized that, different from all existing control schemes employed in a rectifier with an active power decoupling function, the proposed control scheme achieves automatic power decoupling without a power decoupling loop. This enables a low cost controller to be used in the design. The feasibility of the newly modified two-switch rectifier together with the automatic decoupling control are verified through both simulation and experiments on a $100 \mathrm{~W}$ prototype using a $15 \mu \mathrm{F}$ long-lifetime non-E capacitor. A full comparison between the work of [18] and the proposed rectifier is also provided.

\section{Derivation of A New Two-Switch Single-Phase RectifiER}

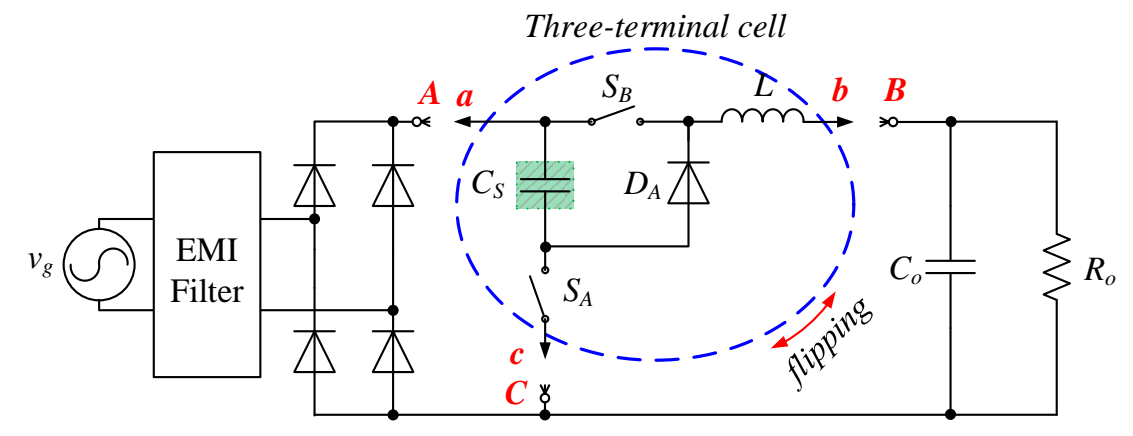

Fig. 1. The basic three-terminal cell that is proposed in [18].

The two-switch topology presented in [18] can be viewed as a basic cell having three terminals labeled as $a, b$, and $c$, connected between a diode-bridge rectifier and an output sink (see Fig. 1). In particular, the rectifier in [18] has a connection of $a-A, b-B, c-C$. Its operation is similar to that of a conventional buck PFC rectifier except that it has an additional power buffering capability. Recall that a rotation of the threeterminal cell of a buck converter could lead to other topologies (e.g. a buck-boost converter and a boost converter) [21]. Here, the basic cell in Fig. 1 can be manipulated in a similar way. One example is to flip it around the terminal $a$, forming a new connection of $a-A, b-C, c-B$. By replacing the switches $S_{A}$ and $S_{B}$ with power MOSFETs and taking care of the voltage polarity, a new two-switch rectifier is derived as shown in 
Fig. 2(a). This new circuit requires new operating principle and control scheme, which are the focuses of this paper.

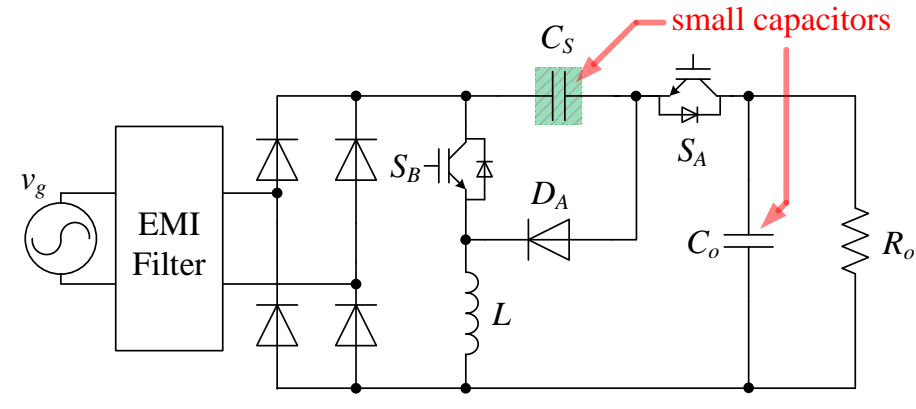

(a)

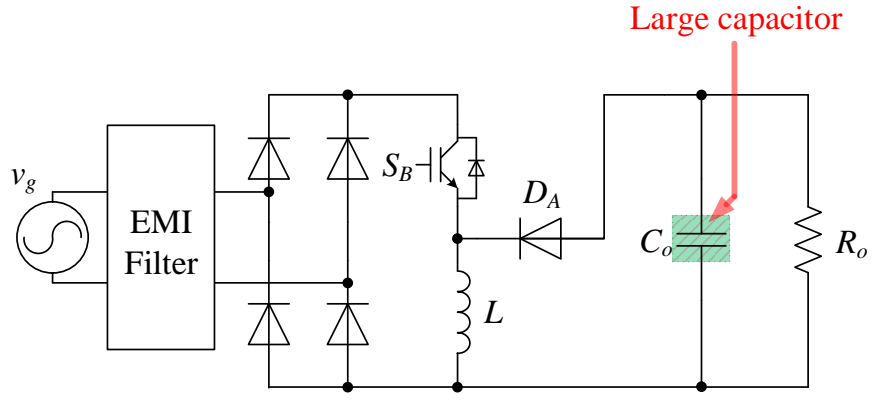

(b)

Fig. 2. Circuit topologies of (a) the proposed two switched PFC rectifier and (b) a conventional buck-boost PFC rectifier.

As it can be observed from Fig. 2, the circuit configuration of the new two-switch rectifier (Fig. 2(a)) is similar to that of a conventional buck-boost PFC rectifier (Fig. 2(b)), except that one extra active switch $S_{A}$ and one energy-buffering capacitor $C_{S}$ are needed. The introduction of these two components creates two new operation states which enable a charging and discharging operation of the capacitor $C_{S}$. Similar to the two-switch buck PFC rectifier described in [18], the new rectifier thus has an additional power decoupling capability, in addition to PFC and output voltage regulation. As a result, the capacitance requirement in the new rectifier is low as compared to that in the conventional buck-boost PFC rectifier. This will lead to an improved circuit design with a higher power density and a higher reliability. A detailed capacitor sizing analysis of the two-switch buck-boost PFC rectifier and the conventional buck-boost PFC rectifier will be provided in Section V.

\section{OPERATING PRINCIPLES}

To facilitate the circuit analysis, Fig. 2(a) is re-drawn as Fig. 3(a) with its electrical equivalent shown in Fig. 3(b). In the equivalent circuit, the effect of the EMI filter has been neglected and $D_{r}$ is the equivalent representation of the front-end diode bridge rectifier. 


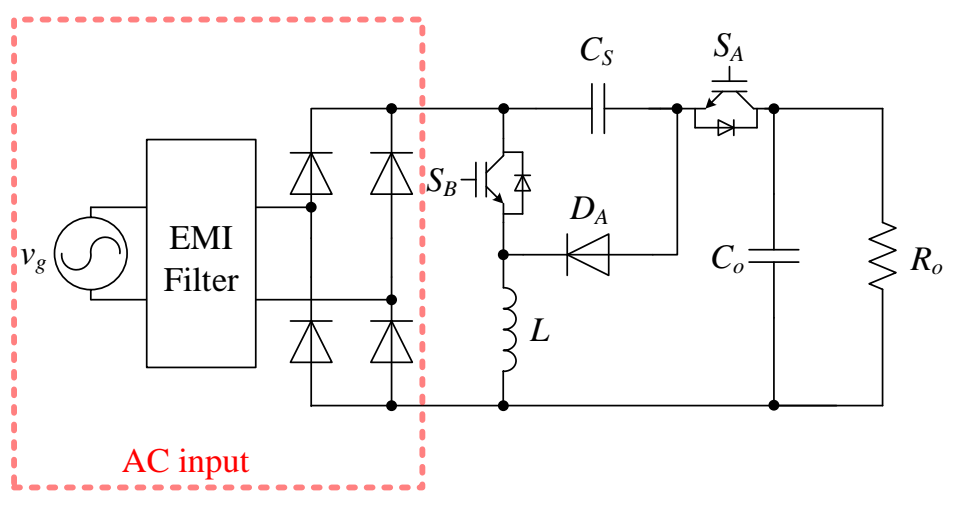

(a)

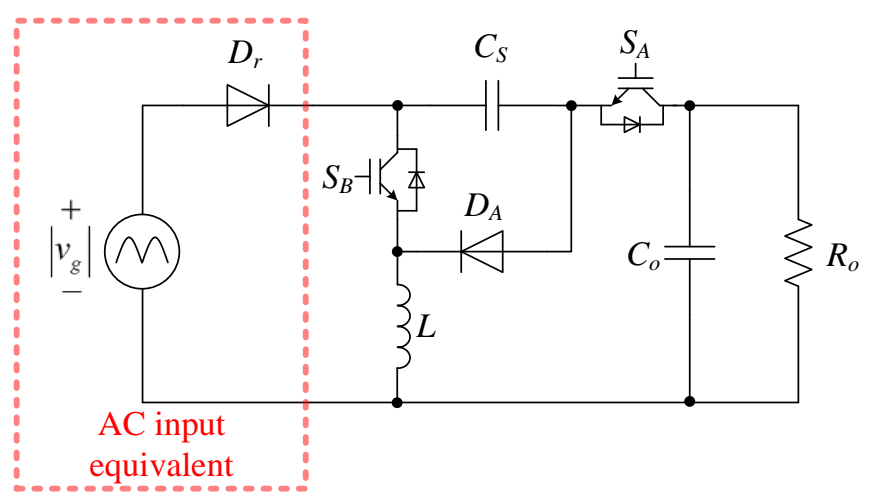

(b)

Fig. 3. (a) Proposed two-switch PFC rectifier and (b) its electrical equivalent circuit.

\section{A. Operating States}

By employing two active switches and assuming a continuous-conduction-mode of operation, the rectifier has four operation states. They are depicted in Fig. 4 as State 1-State 4.

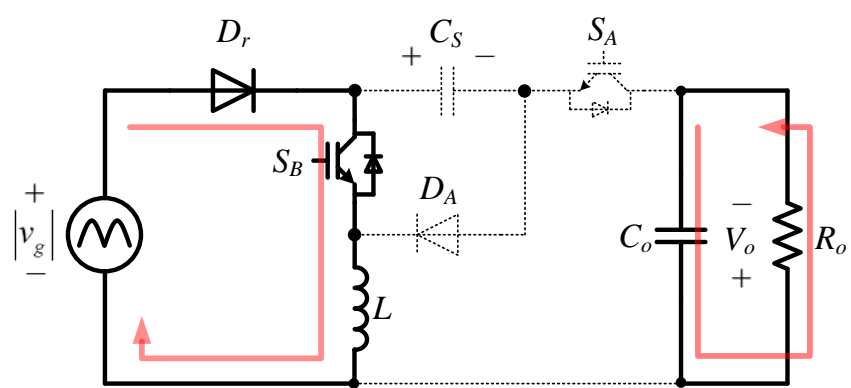

$\left(S_{A}=0, S_{B}=1\right)$

State 1

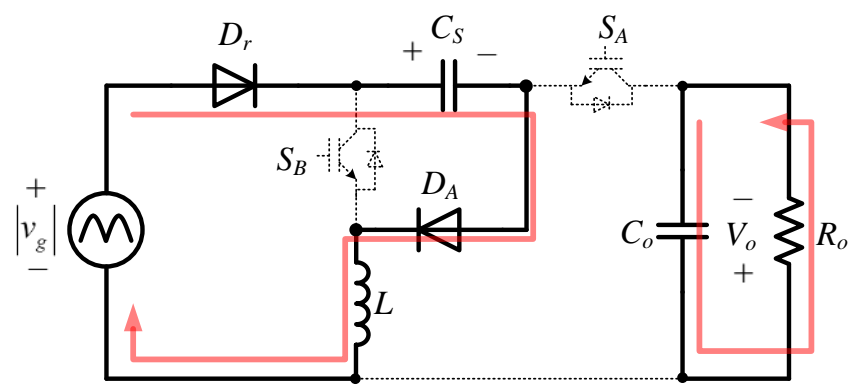

$$
\begin{aligned}
& \left(S_{A}=0, S_{B}=0\right) \\
& \text { State } 3
\end{aligned}
$$

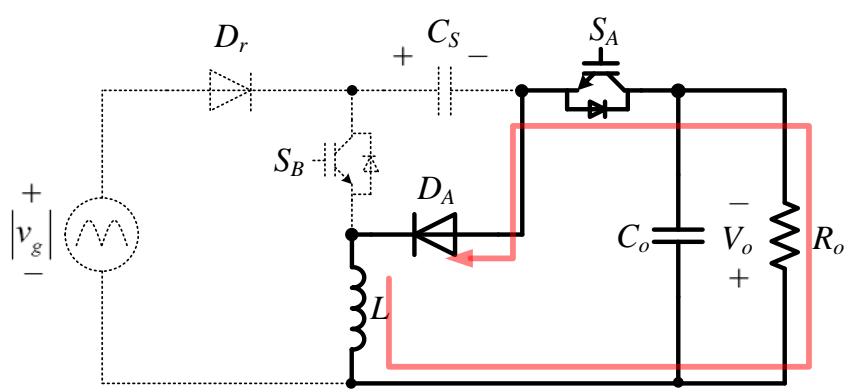

$\left(S_{A}=1, S_{B}=0\right)$

State 2

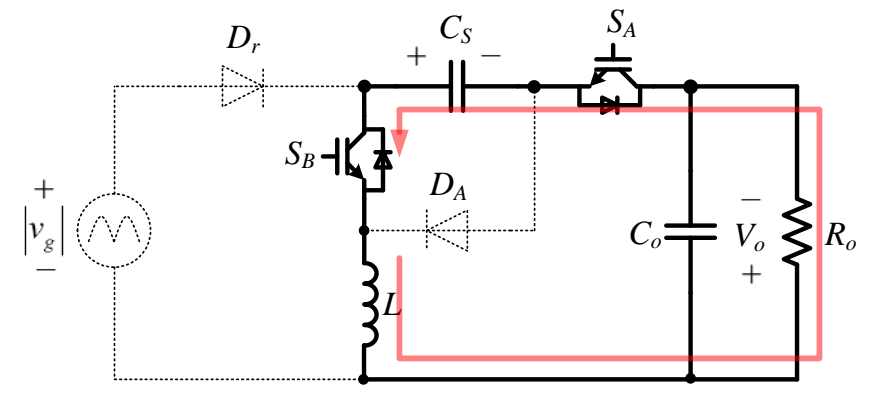

$\left(S_{A}=1, S_{B}=1\right)$

State 4

Fig. 4. Equivalent circuits of the proposed rectifier at the four operation states: State 1-State 4. 
During State 1, the inductor $L$ is charged by the input voltage $\left|v_{g}\right|$ and during State 2, it is discharged to the load $\left(C_{o}\right.$ and $\left.R_{o}\right)$. This process is identical to that of a conventional buck-boost converter since the power-buffering capacitor $C_{S}$ is in idle mode. In State 3 and State $4, C_{S}$ is a part of the power flow path and can operate actively to store and release energy. More specifically, $C_{S}$ is charged by the inductor current in State 3, while $C_{S}$ is discharged to the load in State 4. By controlling the duration of State 3 (capacitor charging state) and State 4 (capacitor discharging state), active power decoupling of the ripple power with $C_{S}$ is viable. Table I summarizes the corresponding charging/discharging states of $C_{S}$ and $L$ with respect to the four switching states.

Table I. Summary of Switching Paterns.

\begin{tabular}{|c|c|c|c|c|}
\hline \hline Operating State & $\boldsymbol{S}_{\boldsymbol{A}}$ & $\boldsymbol{S}_{\boldsymbol{B}}$ & $\boldsymbol{C}_{\boldsymbol{S}}$ & $\boldsymbol{L}$ \\
\hline State 1 & 0 & 1 & Idle & Charge \\
\hline State 2 & 1 & 0 & Idle & Discharge \\
\hline State 3 & 0 & 0 & Charge & Discharge \\
\hline State 4 & 1 & 1 & Discharge & Charge \\
\hline \hline
\end{tabular}

\section{B. Steady-State Cicuit Analysis}

The lengths of State 1-State 4 intervals are denoted as $d_{1} T_{s}, d_{2} T_{s}, d_{3} T_{s}$ and $d_{4} T_{s}$ respectively. Clearly, $d_{1}-$ $d_{4}$ should satisfy

$$
d_{1}+d_{2}+d_{3}+d_{4}=1
$$

Based on Table I, the duty ratios of the switches $S_{A}$ and $S_{B}$ are

$$
\begin{aligned}
& d_{A}=d_{2}+d_{4}, \\
& d_{B}=d_{1}+d_{4} .
\end{aligned}
$$

According to Fig. 4, the average input current $i_{g}$, the output current $i_{o}$ and the capacitor charging current $i_{c}$ over one switching period $T_{s}$ are related to $d_{1}-d_{4}, d_{A}$ and $d_{B}$ as 


$$
\begin{aligned}
& \left|i_{g}\right|=\left(d_{1}+d_{3}\right) i_{L}=\left(1-d_{A}\right) i_{L}, \\
& i_{o}=\left(d_{2}+d_{4}\right) i_{L}=d_{A} i_{L}, \\
& i_{c}=\left(d_{3}-d_{4}\right) i_{L}=\left(1-d_{A}-d_{B}\right) i_{L} .
\end{aligned}
$$

where $i_{L}$ is the average inductor current over $T_{s}$.

According to (6), when $d_{3}>d_{4}$, the average capacitor current over $T_{s}$ is positive and $C_{S}$ is charged, whereas when $d_{3}<d_{4}$, the average capacitor current is negative and $C_{S}$ is discharged. Summation of (4) and (5) yields the steady-state expression of $i_{L}$ as

$$
i_{L}=\left|i_{g}\right|+i_{o}
$$

Hence, the average inductor current is always higher than the average rectified input and the output current. Due to the time-varying term $\left|i_{g}\right|$, the inductor current $i_{L}$ is not a DC quantity and contains a lowfrequency $\mathrm{AC}$ variation. Consequently, there is always a net change of $i_{L}$ per switching period. Thus, the voltage-second balance principle cannot be applied to the inductor $L$ (over the period of $T_{s}$ ) in order to determine the output voltage $v_{o}$ with respect to the duty ratios. Alternatively, based on the power balance principle, one has

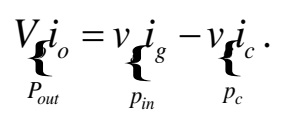

where $v_{c}$ is the voltage of the power-buffering capacitor $C_{S}$. Note that $C_{S}$ only absorbs AC ripple power at steady state. The average power that $C_{S}$ absorbs (i.e., $p_{c}$ ) over a line period $T_{\text {line }}$ is thus zero. Applying an average operator to both sides of (8) over a period of $T_{\text {line }}$ and combining it with (4) and (5) yields

$$
\left\langle v_{o}\right\rangle=\frac{\left\langle v_{g}\left(1-d_{A}\right) i_{L}\right\rangle_{T_{\text {line }}} .}{\left\langle d_{A} i_{L}\right\rangle_{T_{\text {line }}}} .
$$


Equation (9) is similar to the steady-state expression of $v_{o}$ in a DC-DC buck-boost converter. It describes the voltage-buck and -boost capability of the proposed rectifier. As will be shown below, there is no theoretical upper and lower boundary for the output voltage provided that the rectifier operates within the operating constraints.

C. Gate Signal Generation Method and Operating Constraints

According to (4)-(6), the duty ratios $d_{1}, d_{2}$ and $d_{4}$ can be expressed in terms of $d_{3}$ as

$$
\left\{\begin{array}{c}
d_{1}=\frac{\left\langle\left|i_{g}\right|\right\rangle}{\left\langle i_{L}\right\rangle}-d_{3}=\frac{\left\langle\left|i_{g}\right|\right\rangle}{\left\langle\left|i_{g}\right|\right\rangle+\left\langle i_{o}\right\rangle}-d_{3} \\
d_{2}=\frac{\left\langle i_{o}\right\rangle+\left\langle i_{c}\right\rangle}{\left\langle i_{L}\right\rangle}-d_{3}=\frac{\left\langle i_{o}\right\rangle+i_{c}}{\left\langle\left|i_{g}\right|\right\rangle+\left\langle i_{o}\right\rangle}-d_{3} \\
d_{4}=-\frac{\left\langle i_{c}\right\rangle}{\left\langle i_{L}\right\rangle}+d_{3}=-\frac{\left\langle i_{c}\right\rangle}{\left\langle\left|i_{g}\right|\right\rangle+\left\langle i_{o}\right\rangle}+d_{3}
\end{array}\right.
$$

Careful study of (10) suggests that there is a freedom in choosing $d_{3}$. The proper design of $d_{3}$ can reduce the state-transition times, e.g. with three operating states per switching period instead of four. The use of fewer operating states might help to improve the energy efficiency since the power is processed less times. 


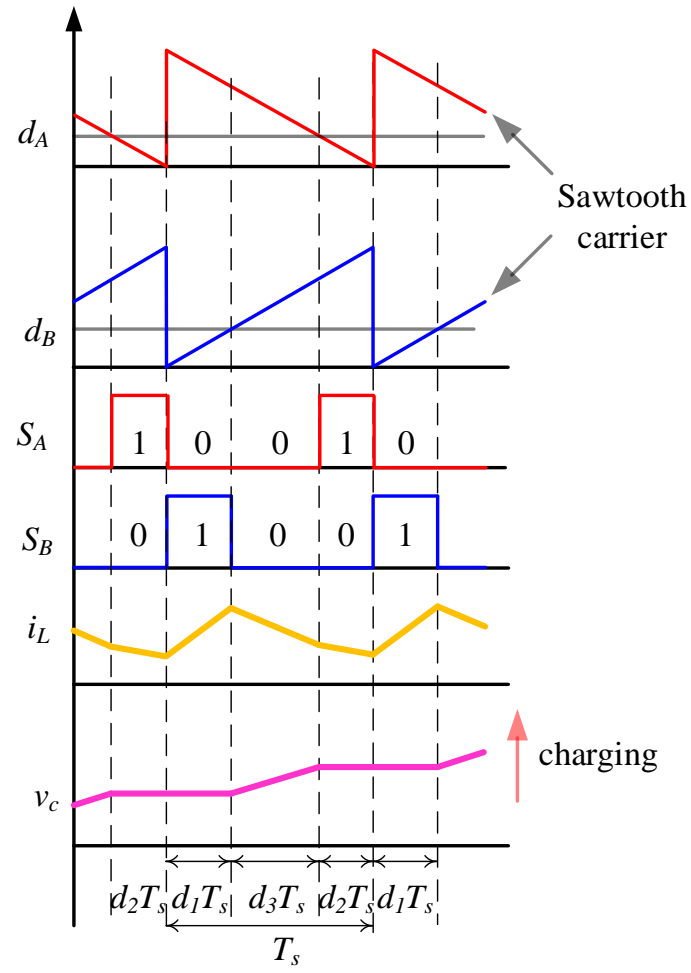

(a)

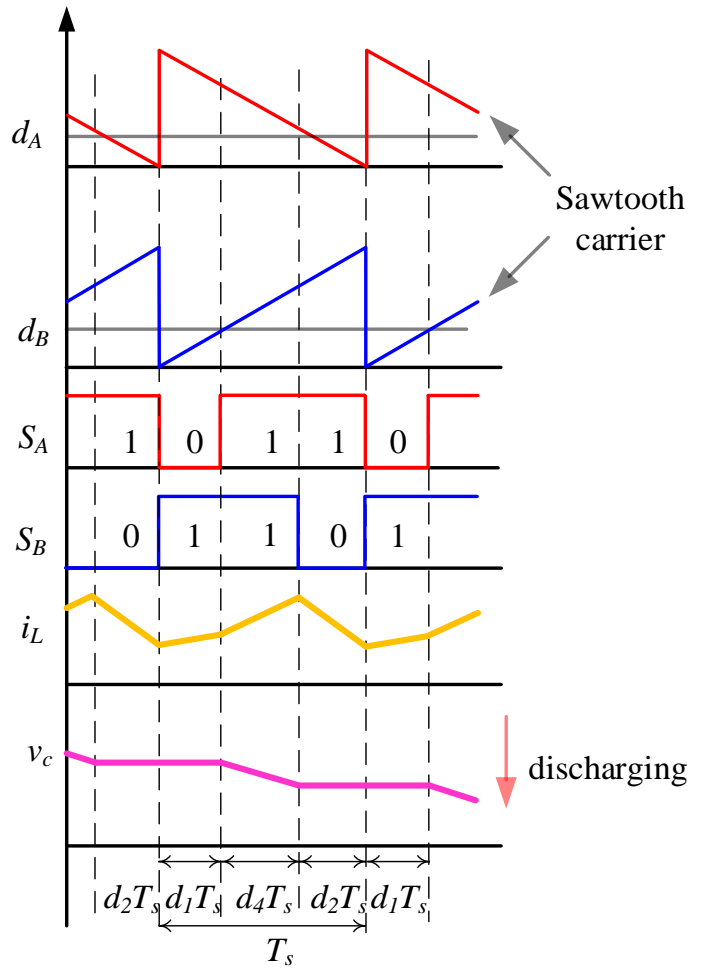

(b)

Fig. 5. Gate signal generation for $S_{A}$ and $S_{B}$ using two out-of-phase sawtooth carriers with associated inductor current and capacitor voltage waveforms when (a) capacitor $C_{S}$ is charged and (b) capacitor $C_{S}$ is discharged.

Fig. 5 shows one possible means of generating the gate signals for $S_{A}$ and $S_{B}$ with three operating states per switching period. The gate signal generation method employs two out-of-phase sawtooth carriers of which the duty cycle commands $d_{A}$ and $d_{B}$ are modulated. As can be seen, during the $C_{S}$ charging phase (Fig. 5(a)), the effective operating states are State 1, State 2 and State 3, while during the $C_{S}$ discharging phase (Fig. 5(b)), the active states are State 1, State 2 and State 4. Mathmatically, this means

$$
\left\{\begin{array}{ll}
d_{1}+d_{2}+d_{3}=1 & \left(i_{c} \geq 0\right) \\
d_{1}+d_{2}+d_{4}=1 & \left(i_{c}<0\right)
\end{array}\right. \text {. }
$$

By combining (10) and (11), the steady-state duty ratios $d_{1}-d_{4}$ can be explicitly resolved as shown in (12) and (13). 


$$
\begin{aligned}
& \left\{\begin{array}{l}
d_{1}=\frac{\left|i_{g}\right|-i_{c}}{i_{L}}=\frac{\left|i_{g}\right|-i_{c}}{\left|i_{g}\right|+i_{o}} \\
d_{2}=\frac{i_{o}}{i_{L}}=\frac{i_{o}}{\left|i_{g}\right|+i_{o}} \quad\left(i_{c} \geq 0\right) \\
d_{3}=\frac{i_{c}}{i_{L}}=\frac{i_{c}}{\left|i_{g}\right|+i_{o}} \\
d_{4}=0
\end{array}\right. \\
& \left\{\begin{array}{l}
d_{1}=\frac{\left|i_{g}\right|}{i_{L}}=\frac{\left|i_{g}\right|}{\left|i_{g}\right|+i_{o}} \\
d_{2}=\frac{i_{o}+i_{c}}{i_{L}}=\frac{i_{o}+i_{c}}{\left|i_{g}\right|+i_{o}} \quad\left(i_{c}<0\right) \\
d_{3}=0 \\
d_{4}=-\frac{i_{c}}{i_{L}}=-\frac{i_{c}}{\left|i_{g}\right|+i_{o}}
\end{array}\right.
\end{aligned}
$$

Note that (12) and (13) are valid only for the modulation method as shown in Fig. 5. Various other carriers, such as two in-phase sawtooth/triangular carriers, can also be used to generate the gate signal. However, the effective operating states within a switching period will become different. Comparisons of different modulation methods and their effects over the system performance are beyond the scope of this paper. Nevertheless, it is interesting to note that the duty cycles $d_{A}$ and $d_{B}$ are independent of the modulation methods. Based on (2), (3) and (10), $d_{A}$ and $d_{B}$ can be derived as

$$
\left\{\begin{array}{l}
d_{A}=\frac{i_{o}}{\left|i_{g}\right|+i_{o}} \\
d_{B}=\frac{\left|i_{g}\right|-i_{c}}{\left|i_{g}\right|+i_{o}}
\end{array} .\right.
$$

To ensure proper circuit operation, $d_{A}, d_{B}$ and $d_{1}-d_{4}$ must be operating within the range of $0-100 \%$. Examination of (12)-(14) yields one operating constraint of the rectifer, that is,

$$
\left\{\begin{array}{ll}
\left|i_{c}\right| \leq\left|i_{g}\right| & \left(i_{c} \geq 0\right) \\
-i_{c} \leq i_{o} & \left(i_{c}<0\right)
\end{array} .\right.
$$


With reference to Fig. 4, a second operating constraint is

$$
\left\langle v_{c}\right\rangle>v_{g}+\left\langle v_{o}\right\rangle
$$

If (16) is violated, diode $D_{r}$ will be forward-biased during State 2 and State 4, and will therefore be falsely turned ON. The operating constraints established in (15) and (16) imply no direct correlation between the input current $i_{g}$ and output current $i_{o}$. Based on the understanding of power balance principle, the rectifier has therefore no limitation on its voltage conversion ratio provided that (15) and (16) are satisfied.

Calculation results

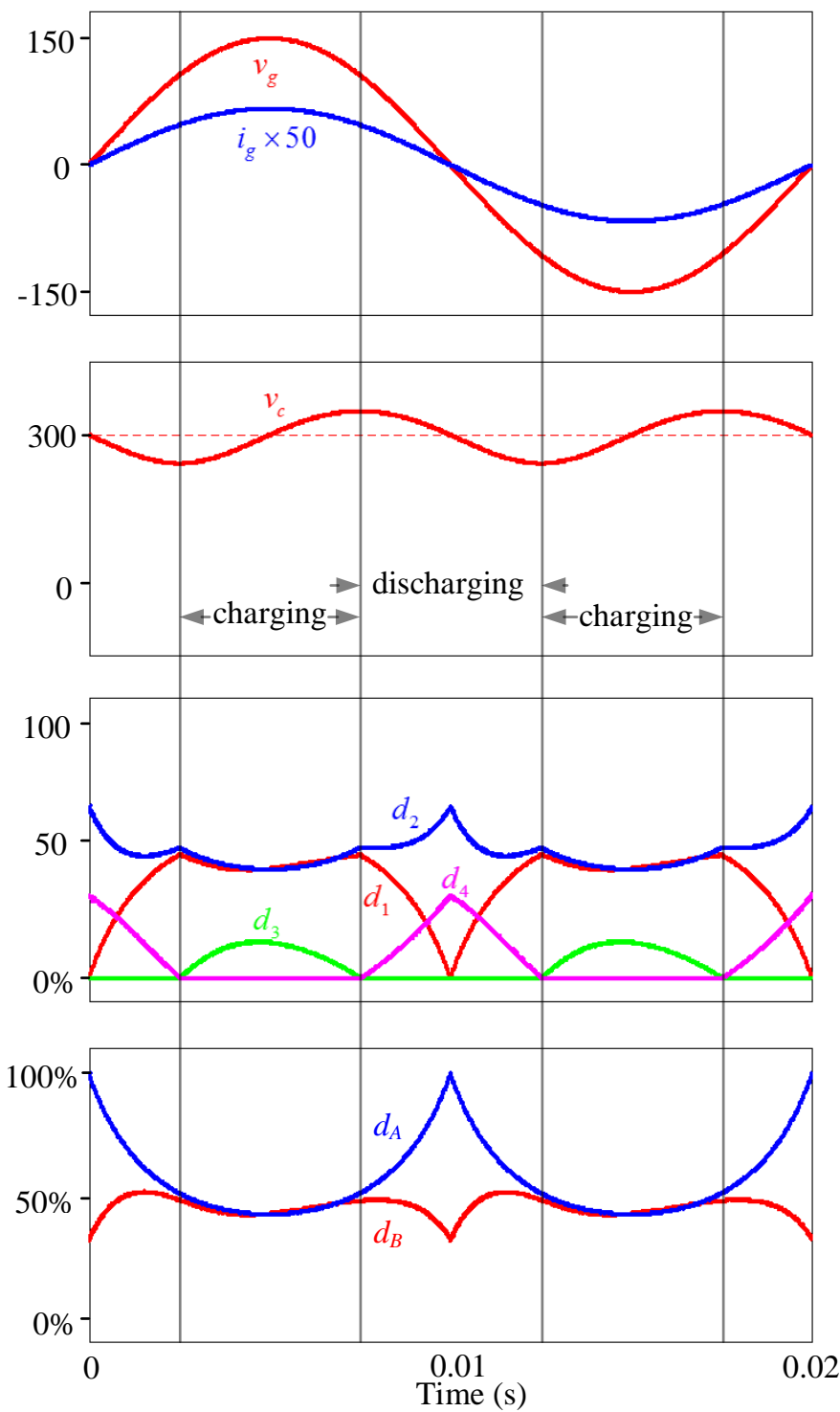

Simulation results
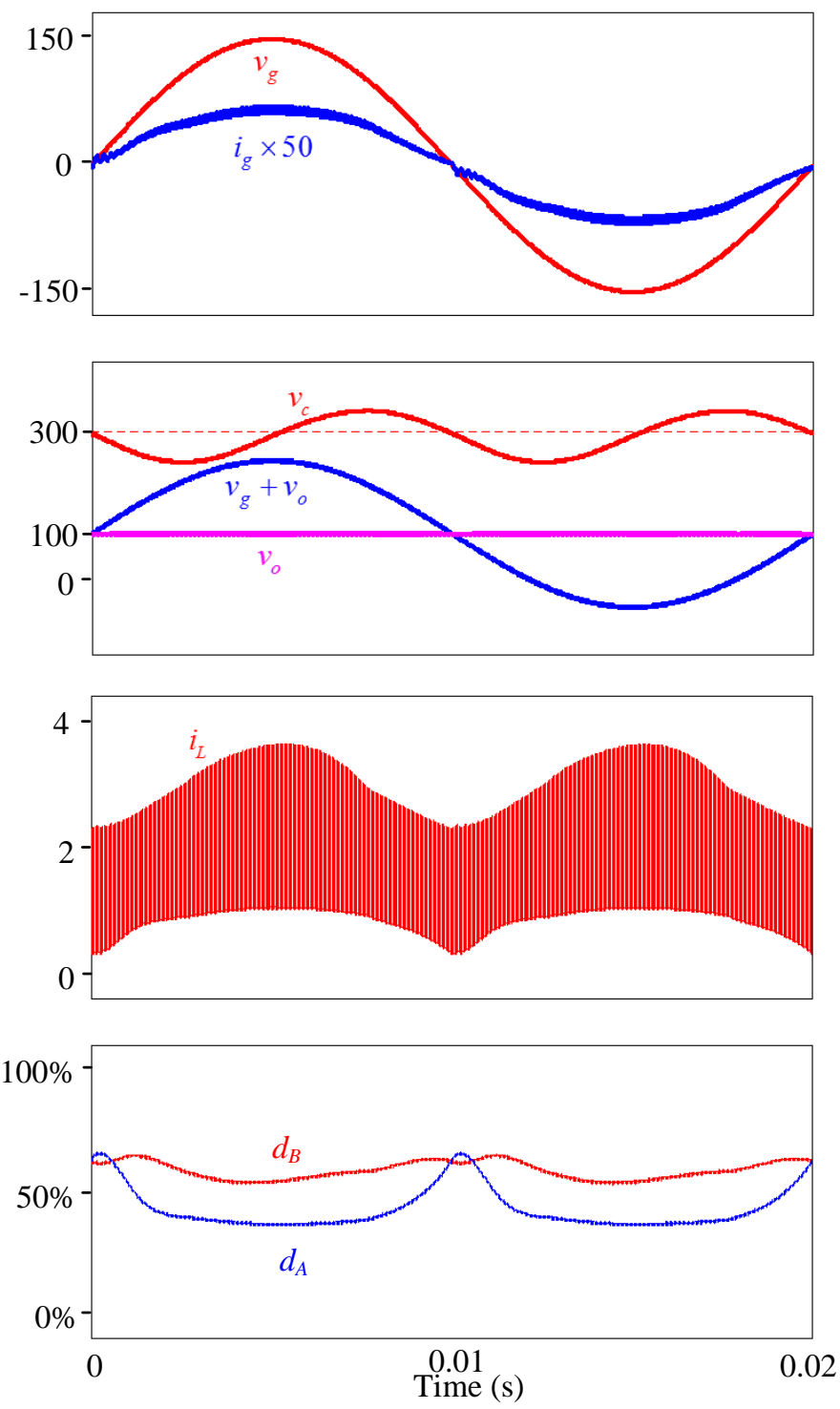
Fig. 6. (a) Calculated and (b) simulated waveforms of duty ratios $d_{1}-d_{4}$ and duty cycles $d_{A}$ and $d_{B}$ versus the waveforms of AC input voltage $v_{g}$, AC input current $i_{g}$ and power- buffering capacitor voltage $v_{c}$.

Fig. 6(a) depicts the calculated $d_{1}-d_{4}, d_{A}$ and $d_{B}$ waveforms based on (12)-(14) during a period of $T_{\text {line }}$ for a $100 \mathrm{~W}$ rectification system (110 V AC input and $100 \mathrm{~V}$ DC output). The detailed calculation parameters can be found in Section V and VII. In the calculation, the power-buffering capacitor $C_{S}$ is assumed to have fully compensated all the double-line frequency ripple power and thus the output power is constant. The results in Fig. 6(a) show that $d_{1}-d_{4}, d_{A}$ and $d_{B}$ all fall within the range of $0-100 \%$. They indicate that the rectifier is properly operated.

\section{Control Strategy With Automatic Power Decoupling}

Ideally, a feed-forward control based simply on the calculation of (12) and (13) can be employed to achieve a desired circuit operation. In practice, such an open-loop control will cause the output voltage, power-buffering capacitor voltage and inductor current to drift from their nominal values, due to the component tolerances, converter non-linearity and power losses. A novel closed-loop control is hence proposed in this paper to compensate these non-idealities. A well-shaped input current and regulated output voltage can therefore be attained.

According to Fig. 4, the state-space equations describing the dynamics of the inductor current $i_{L}$, the output capacitor voltage $v_{o}$ and the power-buffering capacitor voltage $v_{c}$ are, respectively,

$$
\begin{gathered}
L \frac{d i_{L}}{d t}=\left(v_{g}-v_{c}\right)-d_{A}\left(v_{g}+v_{o}-v_{c}\right)+d_{B} v_{c}, \\
C_{o} \frac{d v_{o}}{d t}=d_{A} i_{L}-\frac{v_{o}}{R_{o}} \\
C_{S} \frac{d v_{c}}{d t}=\left(1-d_{A}-d_{B}\right) i_{L},
\end{gathered}
$$


where $R_{o}$ is the load resistance, $d_{A}$ and $d_{B}$ are the control inputs, $v_{g}$ is the system input, $i_{L}, v_{o}$ and $v_{c}$ are the state variables and are also the control outputs.

Equations (17)-(19) indicate that the system dynamics is highly non-linear due to the product operation of the control inputs and the time-varying state variables. Consequently, with $d_{A}$ and $d_{B}$ as control inputs, it is not a trivial task to design a controller for the system in order to achieve a specific dynamic performance.

Since the focus of this paper is to demonstrate the functionality of the proposed two-switch PFC rectifier in performing PFC, output voltage regulation and power decoupling, the controller design here is simplified based on a simple controllability analysis.

The switching functions of $S_{A}$ and $S_{B}$ are respectively defined as $s_{a}$ and $s_{b}$, where $s_{i} \in\{0,1\}$ and $i \in\{a$, $b\} . s_{i}=1$ indicates that the corresponding switch is $\mathrm{ON}$, and $s_{i}=0$ indicates that the corresponding switch is OFF. According to (18), the different situations of the switching action can be described as follows:

when $s_{a}=1, d v_{o} / d t=\left(i_{L}-v_{o} / R_{o}\right) / C_{o}=\left(i_{L}-i_{o}\right) / C_{o}=i_{g} / C_{o} \geq 0$, and $v_{o}$ increases;

when $s_{a}=0, d v_{o} / d t=\left(-v_{o} / R_{o}\right) / C_{o}<0$, and $v_{o}$ decreases.

The above analysis implies that $v_{o}$ has a monotonic relationship with the switching action of $S_{A}$. Thus, $v_{o}$ is controllable via $S_{A}$. On the other hand, with reference to (17) and considering the operating constraint in (16), the dynamics of the inductor current $i_{L}$ are expressed as follows:

- $\quad$ when $s_{a}=1, s_{b}=1, d i_{L} / d t=\left(v_{c}-v_{o}\right) / L>0$, and $i_{L}$ increases;

- $\quad$ when $s_{a}=0, s_{b}=1, d i_{L} / d t=v_{g} / L>0$, and $i_{L}$ increases;

- $\quad$ when $s_{a}=1, s_{b}=0, d i_{L} / d t=-v_{o} / L<0$, and $i_{L}$ decreases;

- $\quad$ when $s_{a}=0, s_{b}=0, d i_{L} / d t=\left(v_{g}-v_{c}\right) / L<0$, and $i_{L}$ decreases.

The above analysis shows that $i_{L}$ has a monotonic relationship with the switching action of $S_{B}$, despite the state of $S_{A}$. Therefore, $i_{L}$ is controllable through $S_{B}$. 


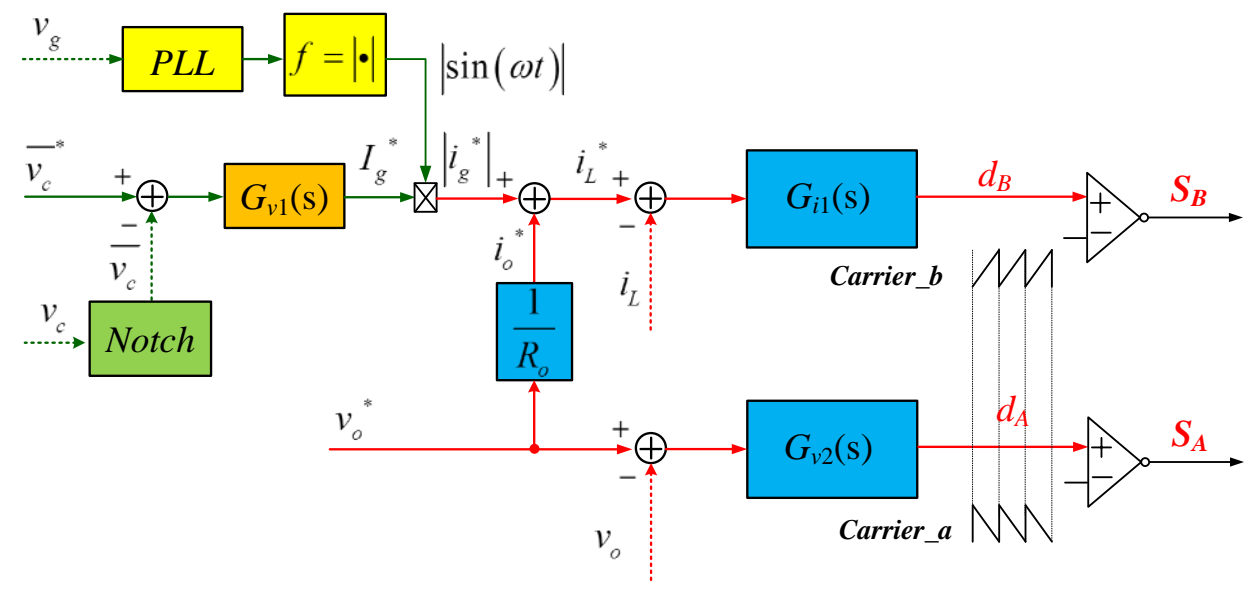

Fig. 7. Control scheme for the proposed two-switch rectifier with automatic power decoupling.

Once the switching actions for $S_{A}$ and $S_{B}$ are determined so that $i_{L}$ and $v_{o}$ are regulated at their desired values, the instantaneous input and output power can be determined. As a result, their power difference (the ripple power) will automatically be transferred to the power-buffering capacitor $C_{S}$. There is no need to involve a power decoupling control for regulating $v_{c}$ which is typically required in conventional rectifiers with power decoupling function. The dynamic variation of $v_{C}$ is mathematically described in (19). The elimination of a sophisticated power decoupling loop greatly simplifies the controller design and enables a low-cost control unit to be used for implementing the control.

Fig. 7 illustrates one possible control scheme for the proposed two-switch rectifier based on the above analysis. Here, $v_{o}$ is controlled by $S_{A}$ via a voltage compensator $G_{v 2}(\mathrm{~s})$ and $i_{L}$ is controlled by $S_{B}$ via a current compensator $G_{i 1}(\mathrm{~s})$. Proportional-Integral-plus-resonant compensators (PIR) are selected for $G_{i 1}(\mathrm{~s})$ and $G_{v 2}(\mathrm{~s})$ to ensure zero steady-state error and to avoid disturbances at double- and high-order line frequencies. The reference signal $i_{L}{ }^{*}$ is obtained based on (7) by summing the rectified input current reference $\left|i_{g}{ }^{*}\right|$ and the output current reference $i_{o}{ }^{*}$. At the same time, $\left|i_{g}{ }^{*}\right|$ is obtained from an outer voltage loop regulating the average value of $v_{c}$, i.e., $\bar{v}_{c}$, at ${\overline{v_{c}}}^{*}$. Note that the use of a small power-buffering capacitor will cause $v_{c}$ to fluctuate significantly at double- and high-order line frequencies. A notch filter with stopping bands at these 
frequencies is thus employed. In order to regulate the average value of $v_{c}$, a low-bandwidth proportionalIntegral compensator $(\mathrm{PI})$ is selected for $G_{v 1}(\mathrm{~s})$.

Fig. 6(b) shows the simulation results of the proposed rectifier using the control scheme shown in Fig. 7. It can be seen that the input current $i_{g}$ is sinusoidal and is in phase with the input voltage $v_{g}$. The output voltage is fairly constant at $100 \mathrm{~V}$ with negligible low frequency ripple. Additionally, the average voltage of the power-buffering capacitor $v_{c}$ is regulated at $300 \mathrm{~V}$ and $v_{c}$ is fluctuating significantly. The low-frequency pulsating waveform of $v_{c}$ indicates that $C_{S}$ is performing the power decoupling function, even though no active power decoupling control is applied. By comparing Fig. 6(a) with Fig. 6(b), one can see that the waveforms in Fig. 6(b) are well predicted, except that there are some deviations in the duty cycles $d_{A}$ and $d_{B}$. These deviations are reasonable and they demonstrate the efforts of the closed-loop control in compensating the non-linearity and power losses of the switching converter.

\section{DESIGN CONSIDERATIONS}

\section{A. Power-Buffering Capacitor Design}

In a single-phase unity-power-factor rectifier, the instantaneous voltage of the power-buffering capacitor [1], [4], [18] is

$$
v_{c}(t)=\sqrt{V_{C \min }{ }^{2}-\frac{P_{o}}{\omega C_{s}}[\sin (2 \omega t)-1]}
$$

where $V_{C \min }$ is the minimum voltage of $v_{c}, P_{o}$ is the output power, and $\omega$ is the line frequency. The expression is derived assuming zero power loss in the converter and zero low-frequency energy storage in the main inductor $L$ and in the output capacitor $C_{o}$. According to (16), a sufficient condition for $V_{C \min }$ is

$$
V_{C \min }>V_{g}+V_{o}
$$

where $V_{g}$ is the peak amplitude of $v_{g}$ and $V_{o}$ is the average value of $v_{o}$.

Based on (20), the maximum value of $v_{c}$ can be obtained as 


$$
V_{C \max }=\sqrt{V_{C \min }^{2}+\frac{2 P_{o}}{\omega C_{s}}} .
$$

The DC voltage rating of $C_{S}$ should be sufficiently higher than that indicated in (22).

On the other hand, the current of $C_{S}$ is

$$
i_{c}(t)=-\frac{P_{o} \cos (2 \omega t)}{\sqrt{V_{C \text { min }}{ }^{2}-\frac{P_{o}}{\omega C_{s}}[\sin (2 \omega t)-1]}} .
$$

When $2 \omega t=\pi, i_{c}$ becomes its maximum, i.e.,

$$
I_{C \max }=\frac{P_{o}}{\sqrt{V_{C \min }{ }^{2}+\frac{P_{o}}{\omega C_{s}}}},
$$

and when $2 \omega t=0, i_{c}$ becomes its minimum, i.e.,.

$$
I_{C \min }=-\frac{P_{o}}{\sqrt{V_{C \min }^{2}+\frac{P_{o}}{\omega C_{s}}}} .
$$

To comply with the operating constraint of (15), a sufficient condition for $I_{C \max }$ and $I_{C \min }$ is

$$
\left\{\begin{array}{l}
I_{C \max } \leq I_{g}+i_{o} \\
-I_{C \min } \leq i_{o}
\end{array} .\right.
$$

where $I_{g}$ is the peak amplitude of the input current $i_{g}$. It can be easily verified that (26) always holds when (21) is met. This means that the capacitance value of $C_{S}$ can be solely determined based on (21).

In practice, $V_{C \max }$ is often pre-specified. Equations (21) and (22) indicate that the minimum capacitance required is 


$$
C_{S \min }=\frac{2 P_{o}}{\omega\left[V_{C \max }^{2}-\left(V_{g}+V_{o}\right)^{2}\right]} .
$$

As a result, a larger value of $V_{C \max }$ leads to a smaller capacitance for $C_{S}$. On the other hand, for a conventional PFC rectifier without active power decoupling, such as the buck-boost type PFC rectifier as shown in Fig. 3(b), the output capacitance requirement is [1], [4], [18]

$$
C_{o}=\frac{P_{o}}{\omega V_{o}{ }^{2} k_{r}},
$$

where $k_{r}$ is the peak-to-peak ripple factor (the ratio of the peak-to-peak variation of $v_{o}$ over $V_{o}$ ).

Based on (27) and (28), the minimum capacitance required for achieving power buffering in a conventional buck-boost PFC rectifier and in the proposed two-switch PFC rectifier at different output voltage levels are plotted in Fig. 8. For the entire range of $V_{o}$, the capacitance value of $C_{S}$ is much smaller than that of $C_{o}$. The two-switch rectifier can hence achieve a more compact and reliable system design.

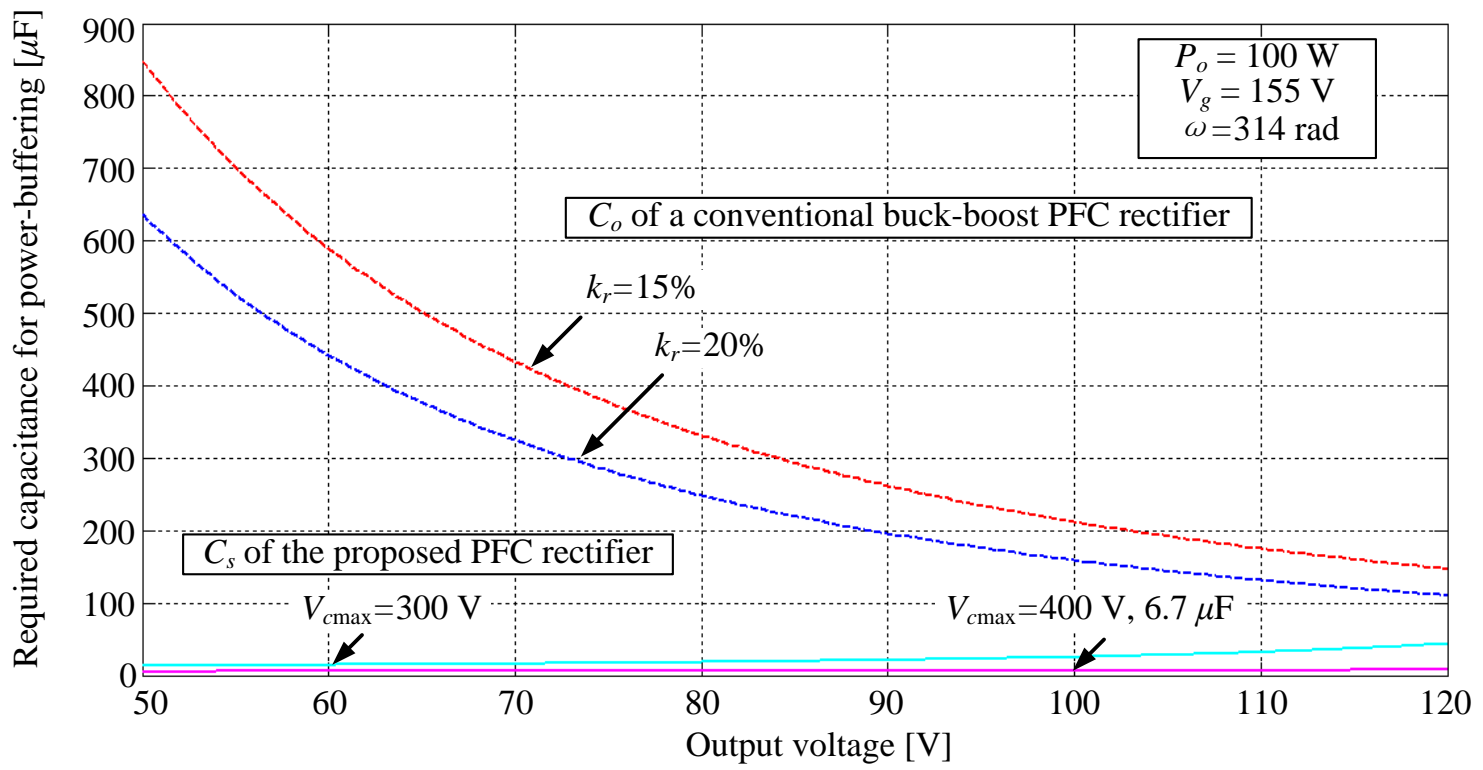

Fig. 8. Power-buffering capacitance requirement for a conventional buck-boost PFC rectifier (with a peak-to-peak ripple factor of $15 \%$ and $20 \%$ ) and for the proposed PFC rectifier (with maximum capacitor voltage of $300 \mathrm{~V}$ and $400 \mathrm{~V}$ ). 


\section{B. Active Switches and Diodes Design}

Table II lists the voltages across the diodes $D_{r}, D_{A}$ and switches $S_{A}, S_{B}$ during State 1-State 4 . The corresponding voltage ratings are also provided. Note that the minimum voltage ratings for $S_{B}$ and $D_{A}$ are equal to the maximum voltage of $v_{c}$, while the ratings for $S_{A}$ and $D_{r}$ are the voltage difference between the maximum $v_{c}$ and $v_{o}$. Low-voltage-rating components can thus be selected for $S_{A}$ and $D_{r}$.

Table II. Voltages and voltage ratings for $D_{r}, D_{A}, S_{A}$ and $S_{B}$.

\begin{tabular}{|c|c|c|c|c|}
\hline \hline Operating State & $\boldsymbol{S}_{\boldsymbol{A}}$ & $\boldsymbol{S}_{\boldsymbol{B}}$ & $\boldsymbol{D}_{\boldsymbol{r}}$ & $\boldsymbol{D}_{\boldsymbol{A}}$ \\
\hline State 1 & $v_{c}-v_{o}-\left|v_{g}\right|$ & 0 & 0 & $v_{c}$ \\
\hline State 2 & 0 & $v_{c}$ & $v_{c}-v_{o}-\left|v_{g}\right|$ & 0 \\
\hline State 3 & $v_{c}-v_{o}-\left|v_{g}\right|$ & $v_{c}$ & 0 & 0 \\
\hline State 4 & 0 & 0 & $v_{c}-v_{o}-\left|v_{g}\right|$ & $v_{c}$ \\
\hline $\begin{array}{c}\text { Minimum voltage } \\
\text { rating }\end{array}$ & $V_{C \max }-V_{o}$ & $V_{C \max }$ & $V_{C \max }-V_{o}$ & $V_{C \max }$ \\
\hline \hline
\end{tabular}

On the other hand, as the inductor current flows through each switching component, the current ratings for $D_{r}, D_{A}, S_{A}$ and $S_{B}$ are identical and should be higher than the maximum inductor current.

\section{Inductor Design}

The two design criteria for the main inductor $L$ are: (i) the high-frequency inductor current ripple should be kept within a pre-specified range, e.g. $\Delta i_{L_{-} \text {rated }}$ and (ii) the rectifier should have a continuous conduction mode (CCM) of operation.

With reference to Fig. 4, the inductor current ripple can be expressed as

$$
\Delta i_{L}=\frac{v_{g}}{L} d_{1} T_{s}=\frac{v_{g}}{L} \frac{\left|i_{g}\right|-i_{o}}{\left|i_{g}\right|+i_{o}} T_{s},
$$

during the charging phase, and 


$$
\Delta i_{L}=\frac{v_{o}}{L} d_{2} T_{s}=\frac{v_{o}}{L} \frac{i_{o}+i_{c}}{\left|i_{g}\right|+i_{o}} T_{s},
$$

during the discharging phase. To meet the design criteria (i), the minimum inductance is given as

$$
L_{\text {min_(i) }}=\operatorname{Min}\left\{\begin{array}{cc}
\frac{v_{g} T_{s}}{\Delta i_{L_{-} \text {rated }}} \frac{\left|i_{g}\right|-i_{c}}{\left|i_{g}\right|+i_{o}} & \text { when } i_{c} \geq 0 \\
\frac{v_{o} T_{s}}{\Delta i_{L_{-} \text {rated }}} \frac{i_{o}+i_{c}}{\left|i_{g}\right|+i_{o}} & \text { when } i_{c}<0
\end{array}\right\}
$$

Meanwhile, to guarantee CCM operation, a sufficient condition is

$$
i_{L_{-} \min }-\Delta i_{L}>0
$$

According to (7), the minimum inductor current $i_{L_{-} \min }$ occurs when $i_{g}=0$, i.e., $i_{L_{-} \min }=I_{o}$. When $i_{g}=0$, the instantaneous input power is zero and the rectifier is operating in capacitor discharging phase with $i_{c}$ at its minimum. Using (30), the minimum inductance needed to meet the design criteria (ii) is

$$
L_{\text {min_(ii) }_{-}}=\left(1+\frac{I_{c \min }}{I_{o}}\right) \frac{T_{s}}{R_{o}} .
$$

Therefore, the minimum $L$ should be

$$
L_{\text {min }}=\operatorname{Min}\left\{L_{\text {min_(i) }}, L_{\text {min_(ii) }}\right\} \text {. }
$$

\section{Gate Driving Method}

Gate driving of the two active switches can be achieved via a high and low side driving IC, such as IR2102 [22]. A typical gate driving diagram is depicted in Fig. 9, of which the Com node of the driving IC is connected to the circuit ground (the source of $S_{A}$ ), and the switching node $V_{s}$ is connected to the node $X$ (the source of $S_{B}$ ). According to Fig. 4, whenever the rectifier enters into State 2 (i.e., $S_{A}$ and $D_{A}$ are conducting), the node $X$ (or the switching node $V_{s}$ ) will be connected to the ground and the bootstrap capacitor $C_{b s}$ will be 
charged by $V_{c c}$ (i.e., $15 \mathrm{~V}$ ) through $D_{b s}$. The charge stored in $C_{b s}$ will then be used for driving $S_{B}$ during State 1 and/or State 4. This process is repeated for every switching period.

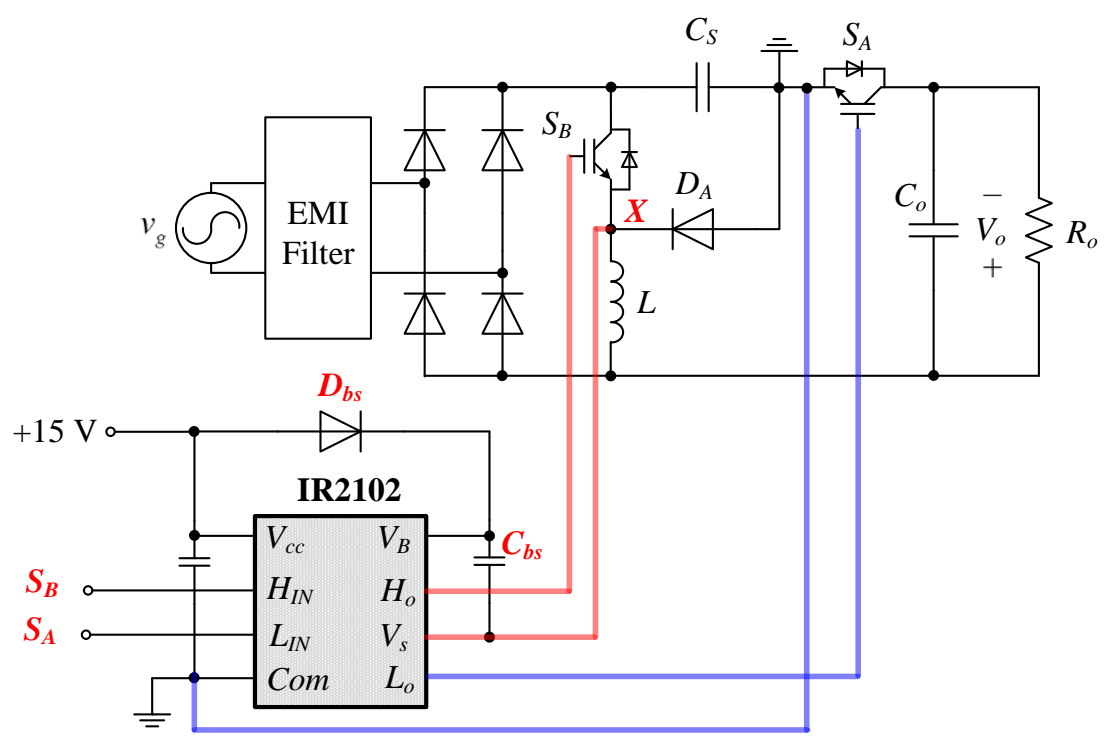

Fig. 9. Gate driving circuit using a high and low side driver IR2102.

The power supply $V_{c c}$ of the driving IC and other control ICs can be obtained in a similar way as that in a conventional PFC rectifier [23]. During the converter start-up, a Resistor-Capacitor network behind the diode bridge rectifier will provide the initial energy for the driving IC, while during the steady state, a coupled winding from the inductor $L$ will supply the required energy.

\section{E. Start-up Protection}

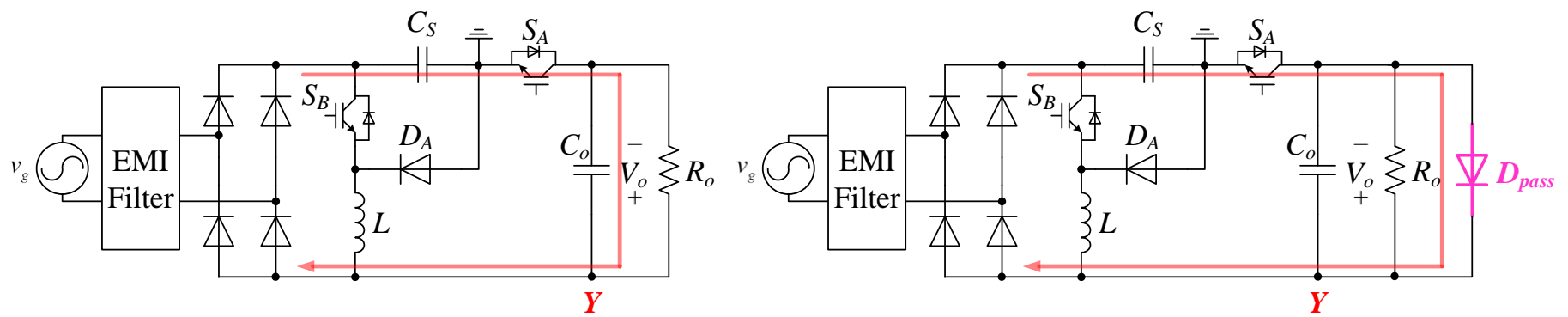

(a)

(b)

Fig. 10. Flow path of the inrush current (a) without a bypass diode and (b) with a bypass diode. 

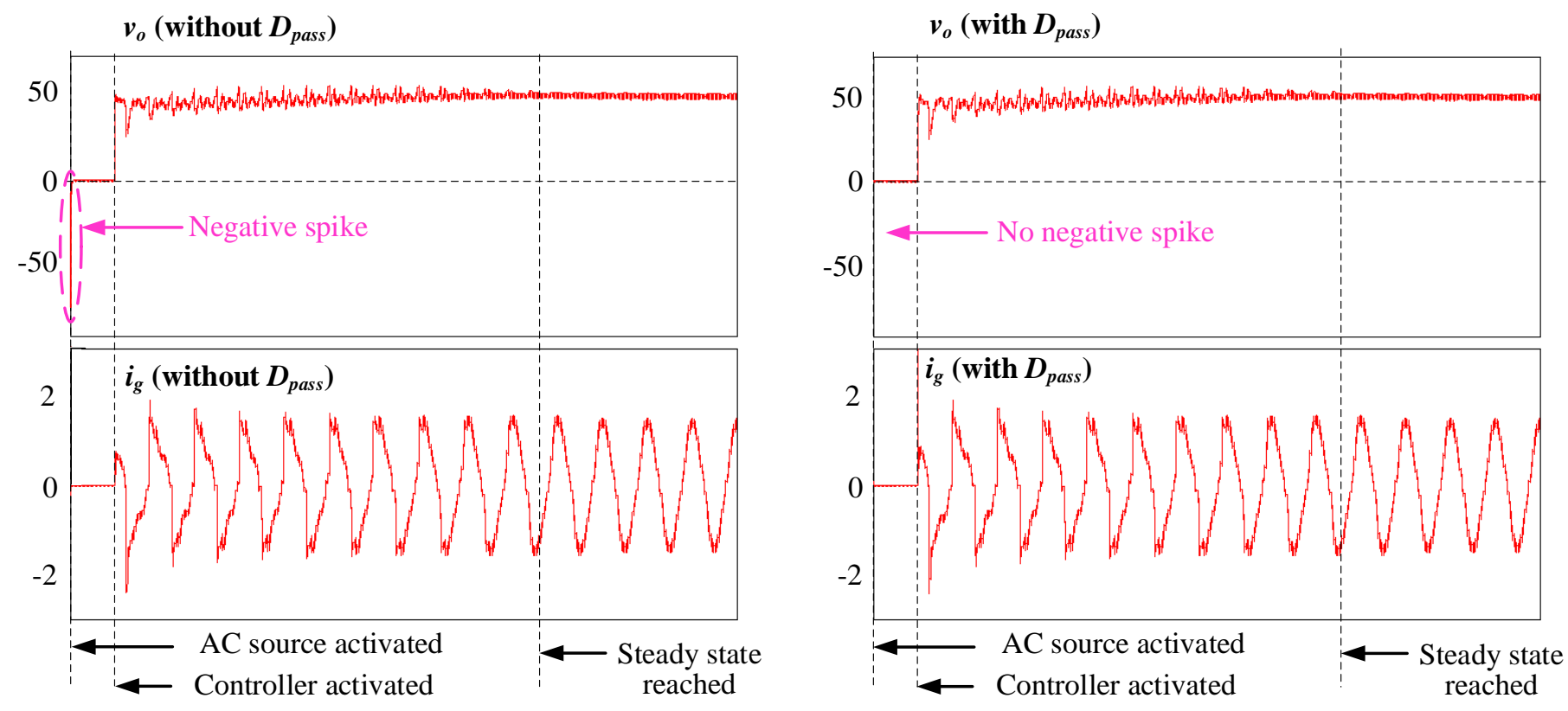

Fig. 11. Simulated start-up waveforms of the proposed rectifier (a) without a bypass diode and (b) with a bypass diode.

Care must be taken during the start-up period. As indicated in Fig. 10(a), when the AC source is initially activated, there will be an inrush current flowing through the power buffering capacitor $C_{s}$, the body diode of $S_{A}$ and the load $\left(C_{o}\right.$ and $\left.R_{o}\right)$. Unfortunately, the current direction through $C_{o}$ and $R_{o}$ is reversed to that in the steady-state operation. This will lead to a short negative spike in $v_{o}$ during the start-up (Fig. 11(a)) and the load can be potentially damaged if it cannot withstand a negative voltage.

A simple solution is shown in Fig. 10(b) where an antiparallel diode $D_{\text {pass }}$ is augmented in parallel with the load. During the start-up, $D_{\text {pass }}$ will be forward biased by the inrush current and the load is refrained from a negative current flowing through it. Therefore, the output voltage will be immune from an undesired negative voltage spike (Fig. 11(b)).

\section{Comparison of The two-Switch Buck Rectifier With The Proposed two-Switch Buck-Boost RECTIFIER}

By following the similar procedures described in Section III-V, one is able to examine the two-switch buck recitifier reported in [18]. Full comparisons between the work in [18] and the proposed two-switch buck-boost rectifier are summarized in Table III. 
Table III. Full Comparison of the two-switch buck rectifier with the proposed two-switch buck-boost rectifier.

\begin{tabular}{|c|c|c|c|}
\hline & Two-switch buck rectifier[18] & $\begin{array}{l}\text { Two-switch buck-boost } \\
\text { rectifier (proposed) }\end{array}$ & $\begin{array}{c}\text { Comments: } \\
\text { Proposed over [18] } \\
\end{array}$ \\
\hline $\begin{array}{c}\text { Static Voltage } \\
\text { Conversion } \\
\text { Ratio }\end{array}$ & $V_{o}=\left\langle v_{g}\left(1-d_{A}\right)\right\rangle_{T_{\text {Tine }}}$ & $V_{o}=\frac{\left\langle v_{g}\left(1-d_{A}\right) i_{L}\right\rangle_{T_{\text {line }}}}{\left\langle d_{A} i_{L}\right\rangle_{T_{\text {line }}}}$ & Wider range \\
\hline Maximum $V_{o}$ & $0.5 V_{g \_ \text {peak }}$ & Unlimited & Larger \\
\hline $\begin{array}{c}\text { Voltage rating } \\
D_{r} \\
\end{array}$ & $V_{C \max }$ & $V_{C \max }-V_{o}$ & Lower \\
\hline $\begin{array}{c}\text { Voltage rating } \\
S_{A} \\
\end{array}$ & $V_{C \max }$ & $V_{C \max }-V_{o}$ & Lower \\
\hline $\begin{array}{c}\text { Voltage rating } \\
D_{A} \\
\end{array}$ & $V_{C \max }$ & $V_{C \max }$ & Same \\
\hline $\begin{array}{c}\text { Voltage rating } \\
S_{B} \\
\end{array}$ & $V_{C \max }$ & $V_{C \max }$ & Same \\
\hline Gate driving & A high and low side driving IC & A high and low side driving IC & Same \\
\hline $\begin{array}{l}\text { Inductor } \\
\text { current } i_{L}\end{array}$ & $I_{o}$ & $I_{o}+\left|i_{g}\right|$ & Larger \\
\hline Minimum $v_{C}$ & $V_{g}$ & $V_{g}+V_{o}$ & Larger \\
\hline $\begin{array}{c}V_{o} \\
\text { at Star-up }\end{array}$ & Positive & $\begin{array}{c}\text { A short negative spike } \\
\text { (Solved by adding } D_{\text {pass }} \text { ) }\end{array}$ & - \\
\hline Duty cycle: $d_{A}$ & $1-\frac{\left|i_{g}\right|}{I_{o}}$ & $\frac{I_{o}}{I_{o}+\left|i_{g}\right|}$ & \\
\hline Duty cycle: $d_{B}$ & $\frac{\left|i_{g}\right|-i_{c}}{I_{o}}$ & $\frac{\left|i_{g}\right|-i_{c}}{I_{o}+\left|i_{g}\right|}$ & \\
\hline $\begin{array}{c}\text { Inductor } \\
\text { current ripple } \\
\Delta i_{L}\end{array}$ & $\left\{\begin{array}{l}\frac{v_{g}-V_{o}}{L} \frac{\left|i_{g}\right|-i_{c}}{I_{o}} T_{s} \quad\left(\text { when } i_{c} \geq 0\right) \\
\frac{V_{o}}{L} \frac{I_{o}-\left|i_{g}\right|+i_{c}}{I_{o}} T_{s} \quad\left(\text { when } i_{c}<0 \text { and } v_{g}>\right. \\
\frac{v_{c}-V_{o}}{L} \frac{-i_{c}}{I_{o}} T_{s} \quad\left(\text { when } i_{c}<0 \text { and } v_{g}<V_{o}\right)\end{array}\right.$ & $\begin{cases}\frac{v_{g}}{L} \frac{\left|i_{g}\right|-i_{c}}{\left|i_{g}\right|+I_{o}} T_{s} & \text { when } i_{c} \geq 0 \\
\frac{V_{o}}{L} \frac{I_{o}+i_{c}}{\left|i_{g}\right|+I_{o}} T_{s} & \text { when } i_{c}<0\end{cases}$ & See Fig. 12. \\
\hline
\end{tabular}

Table III clearly shows that the two-switch buck-boost rectifier has the merits of wider output voltage range and lower voltage rating requirements for $S_{A}$ and $D_{A}$, as compared to the two-switch buck rectifier. However, the two-switch buck-boost rectifier mandates a higher current rating for the inductor $L$ and a higher voltage rating for the power-buffering capacitor $C_{S}$.

Table III also lists the duty cycles $\left(d_{A}\right.$ and $\left.d_{B}\right)$ and the inductor current ripple $\left(\Delta i_{L}\right)$ of the two rectifiers. To facilitate the comparison, the 3-D dynamics of $d_{A}, d_{B}$ and $\Delta i_{L}$ within a line period at different output voltages $(10 \mathrm{~V}$ to $75 \mathrm{~V})$ are ploted as shown in Fig. 12. It can be observed that (i) the variation ranges of $d_{A}$ 
and $d_{B}$ within a line period are wider for the two-switch buck rectifier than that for the two-switch buckboost rectifier and (ii) the maximum inductor current ripple is larger in the former than that for the latter. The second observation suggests that, based on the same inductor current ripple requirement, an inductor $L$ with a smaller inductance value can be selected for the two-switch buck-boost rectifier.

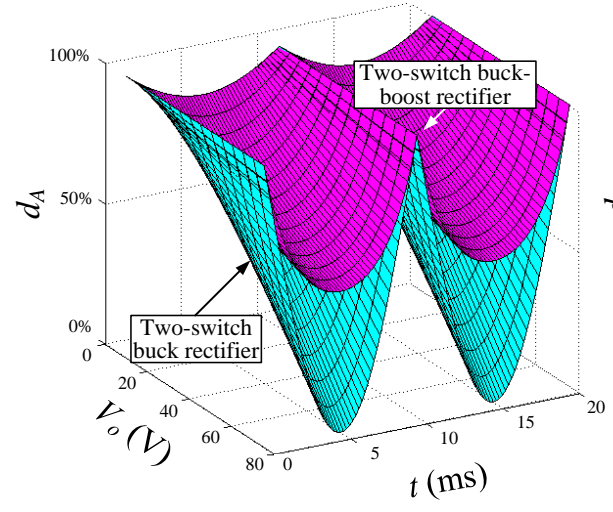

(a)

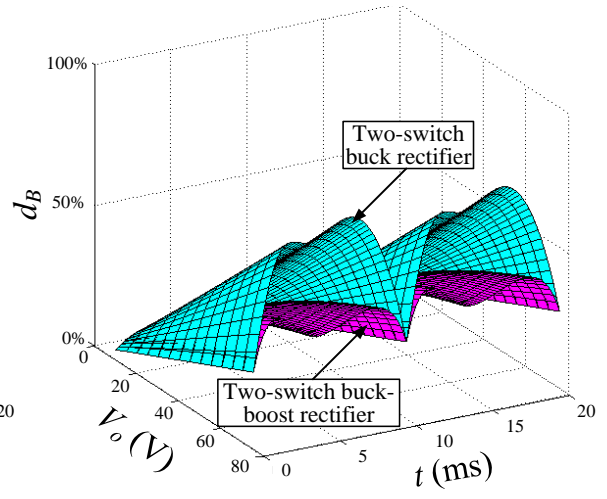

(b)

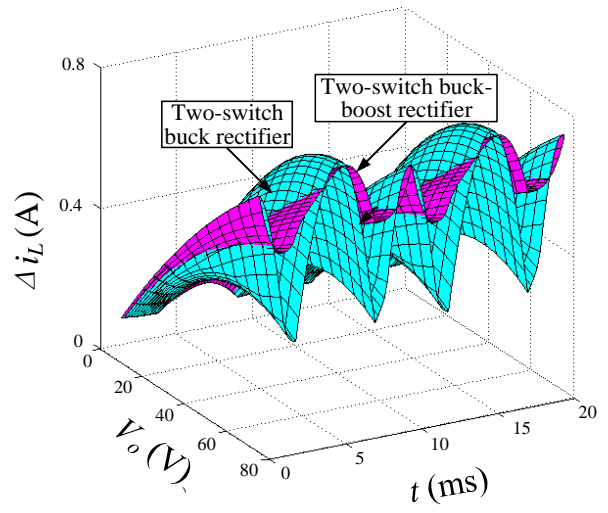

(c)

Fig. 12. 3-D comparison of the two-switch buck PFC rectifier reported in [18] and the proposed two-switch buck-boost PFC rectifier with respect to (a) $d_{A}$ (b) $d_{B}$ and (c) $\left(v_{g}=150 \mathrm{~V}, C_{S}=15 \mu \mathrm{F}, L=3 \mathrm{mH}, f_{s w}=25 \mathrm{kHz}\right.$ and $\left.T_{\text {line }}=20 \mathrm{~ms}\right)$.

At $V_{o}=75 \mathrm{~V}$ (i.e., half of the peak input voltage), the minimum $d_{A}$ in the two-switch buck rectifier decreases to zero. This again verifies that the maximum output voltage has been reached. As for the twoswitch buck-boost rectifier, there are still some operating margins for $d_{A}$ and $d_{B}$. Thus, the rectifier's output voltage is not bounded at half of the peak input voltage.

\section{EXPERIMENTAL VERIFICATION}

Table IV. Key Simulation and Experiment Parameters.

\begin{tabular}{|c|c|c|c|}
\hline Parameters & Values & Parameters & Values \\
\hline Rated power $P_{o}$ & $100 \mathrm{~W}$ & Line frequency & $50 \mathrm{~Hz}$ \\
\hline Peak AC voltage & $155 \mathrm{~V}$ & $\begin{array}{l}\text { EMI filter cut-off } \\
\text { frequency }\end{array}$ & $1.2 \mathrm{kHz}$ \\
\hline DC output voltage $V_{o}$ & $30-100 \mathrm{~V}$ & Switching frequency & $25 \mathrm{kHz}$ \\
\hline Output capacitor $C_{o}$ & $10 \mu \mathrm{F} / 150 \mathrm{~V}$ & Inductor $L$ & $3.5 \mathrm{mH}$ \\
\hline Power-buffering capacitor $C_{S}$ & \multicolumn{2}{|c|}{$15 \mu \mathrm{F} / 500 \mathrm{~V}$} & \multirow{2}{*}{$\begin{array}{l}V_{R R M}: 400 \mathrm{~V}, I_{F}: 3 \mathrm{~A} \\
V_{F}: 1.0 \mathrm{~V}, T_{r r}=50 \mathrm{n}\end{array}$} \\
\hline Diode bridge & \multicolumn{2}{|c|}{$\begin{array}{c}\text { UF5404-E3/54 } \\
\text { (Vishay Semiconductor) }\end{array}$} & \\
\hline Diode $D_{A}$ & SCS20 & & $\mathrm{V}, I_{F}: 6 \mathrm{~A}$ \\
\hline
\end{tabular}




\begin{tabular}{l|c|c} 
& (Rohm Semiconductor) & $V_{F}: 1.35 \mathrm{~V}, T_{r r}=0 \mathrm{~ns}$ \\
\hline \multirow{2}{*}{$S_{A}$ and $S_{B}$} & AOT20S60L & $V_{D S}: 600 \mathrm{~V}, R_{\mathrm{DS}(\mathrm{ON})}: 0.199 \Omega$ \\
& (Alpha \& Omega Semiconductor Inc.) & $T_{r}: 32 \mathrm{~ns}, T_{f}: 30 \mathrm{~ns}$ \\
\hline
\end{tabular}

A $100 \mathrm{~W}$ prototype for $\mathrm{AC}$ input of $110 \mathrm{Vrms} / 50 \mathrm{~Hz}$ with the component specifications given in Table IV has been constructed and tested. The circuit configuration is based on Fig. 2(a). A high and low side gate driver IR2102 and the start-up-protection diode are adopted. The front-end EMI filter in the prototype is a conventional $\pi$-shape $C$ - $L$ - $C$ filter with a cut-off frequency of $1.2 \mathrm{kHz}$. To reduce the switching loss and conduction loss, MOSFETs with low drain-source on-resistance $\left(R_{D C(\mathrm{ON})}\right)$ and junction charges are selected for $S_{A}$ and $S_{B}$. In addition, Silicon-Carbide (SiC) diode with zero reverse recovery charge is chosen for $D_{A}$. Finally, the power-buffering capacitor $C_{S}$ is selected based on the design curves illustrated in Fig. 8. A $15 \mu \mathrm{F}$ film capacitor with long lifetime is chosen.

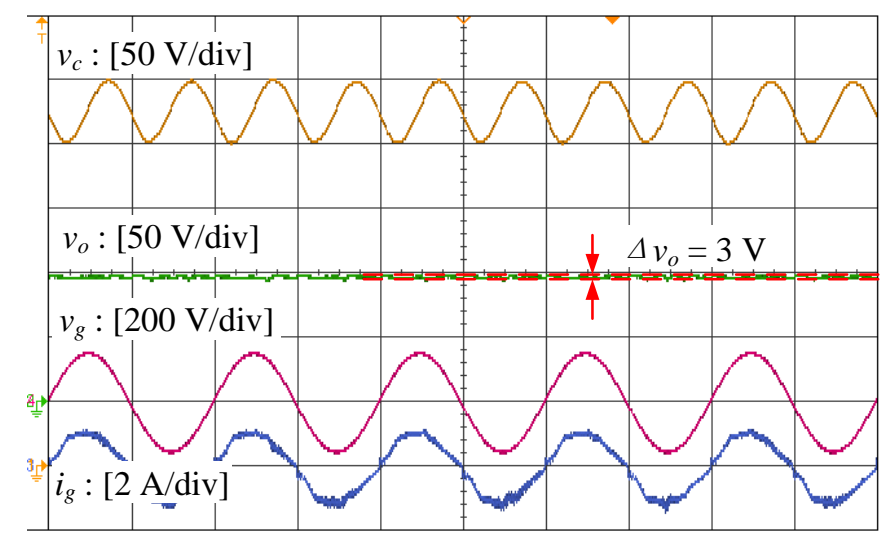

Time : [10 ms/div]

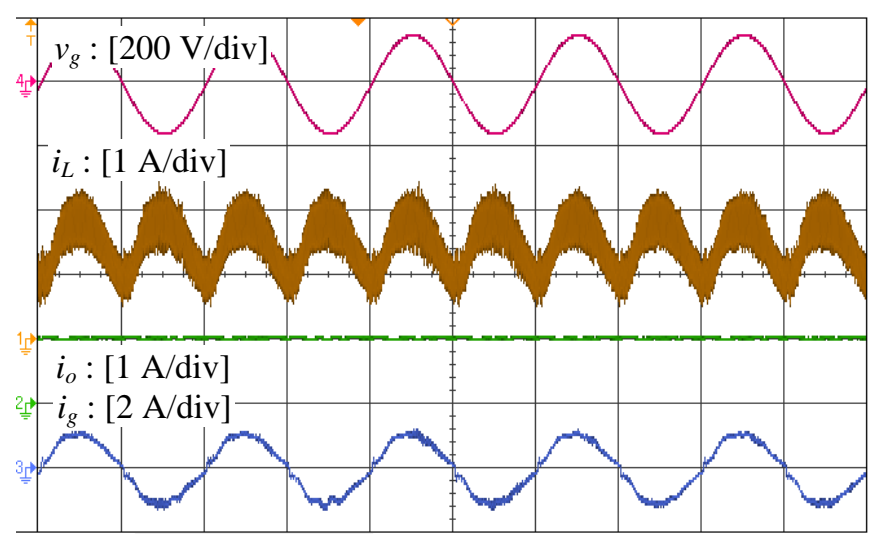

Time : [10 ms/div]

(a)

(b)

Fig. 13. Measured steady-state (a) voltage and (b) current waveforms of the two-switch buck-boost PFC rectifier.

Fig. 13 (a) shows the steady-state waveforms of the input voltage $v_{g}$, line current $i_{g}$, output voltage $V_{o}$ and the voltage of the power-buffering capacitor $v_{c}$. A sinusoidal line current that is in phase with the line voltage has been obtained. In addition, $v_{o}$ is precisely regulated at $100 \mathrm{~V}$ with a peak-peak ripple of merely $3 \mathrm{~V}$ (i.e., $3 \%$ of the average output voltage). The low-frequency varying waveform of $v_{c}$ indicates that $C_{S}$ is 
performing the power decoupling function. The measured $v_{c}$ is varying between $250 \mathrm{~V}$ and $300 \mathrm{~V}$ for an output power of $100 \mathrm{~W}$. The result is consistent with (28).

In Fig. 13(b) the corresponding current waveforms of the rectifier are shown. As predicted in (7), which shows that the average inductor current $i_{L}$ is equal to the averaged sum of the rectified line current and the output current, the measured $i_{L}$ in Fig. 13(b) is always larger than the output current and is low-frequency pulsating.

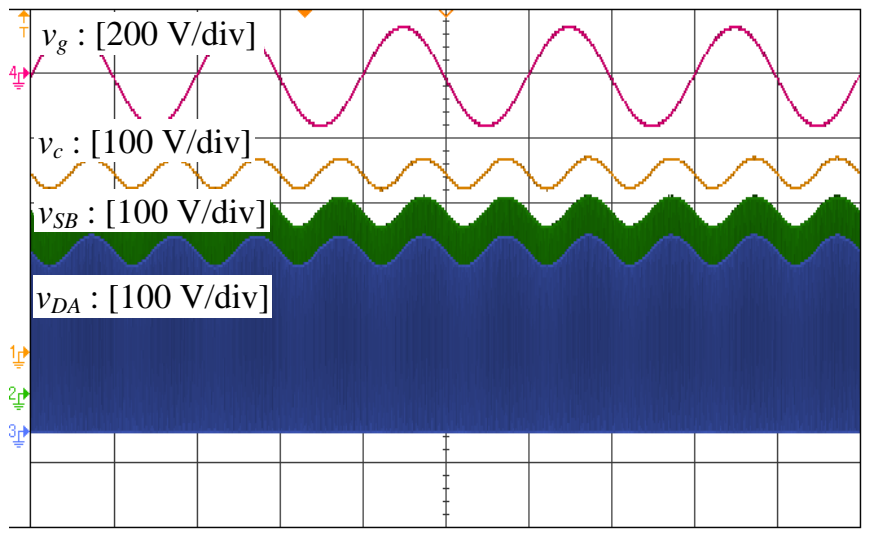

Time : [10 ms/div]

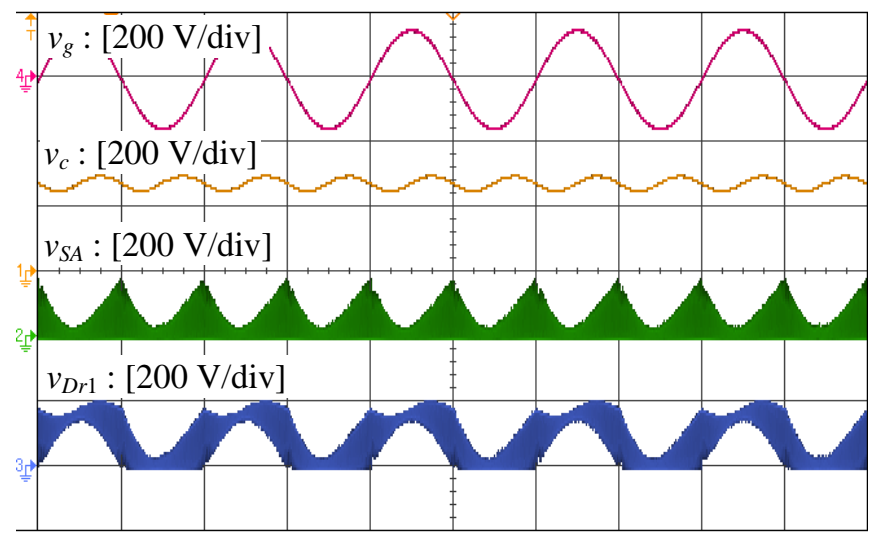

Time : [10 ms/div]

(a)

(b)

Fig. 14. Measured voltage waveforms for (a) $C_{S}, S_{B}, D_{A}$ and AC input and (b) $C_{S}, S_{A}, D_{r l}$ and AC input.

Fig. 14 depicts the voltage waveforms of the switching devices. The voltage of the power-buffering capacitor $v_{c}$ is always applied to the switch $S_{B}$ and the diode $D_{A}$ (Fig. 14(a)), whereas a differential voltage of $v_{c}-v_{o}-\left|v_{g}\right|$ is imposed on $S_{A}$ and the diode bridge (only one out of the four diode is measured here) (Fig. 14(b)). Due to the low voltage applied, $S_{A}$ and the diode bridge should have relatively smaller switching losses (including the diode reverse recovery losses) than those of $S_{B}$ and $D_{A}$.

Fig. 15 shows the switching waveforms of the inductor current and capacitor voltage with the gate driving signals of $S_{A}$ and $S_{B}$. During the discharging phase (viewpoint A), the operating states are State 1, State 2 and State 4. During the charging phase (viewpoint C), the operating states are State 1, State 2 and State 3. During the transition interval from the discharging phase to the charging phase (viewpoint B), the 
period of State 4 gradually decreases to zero and that of State 3 increases. For all the operating points examined, the maximum number of operating states per switching period is three. These measurements confirm the feasibilities of the proposed gate signal generation method for minimizing the state-transition times.

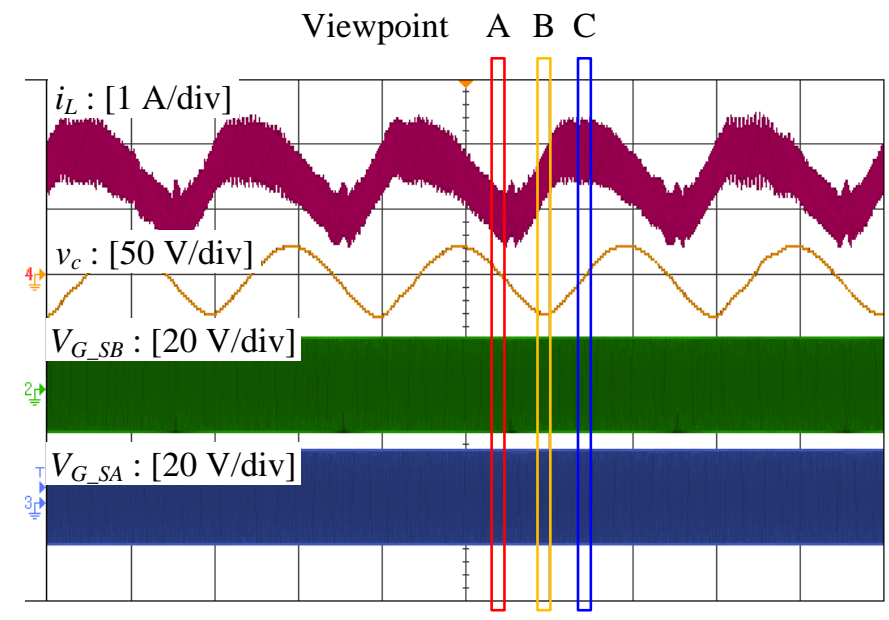

Time : [5 ms/div]

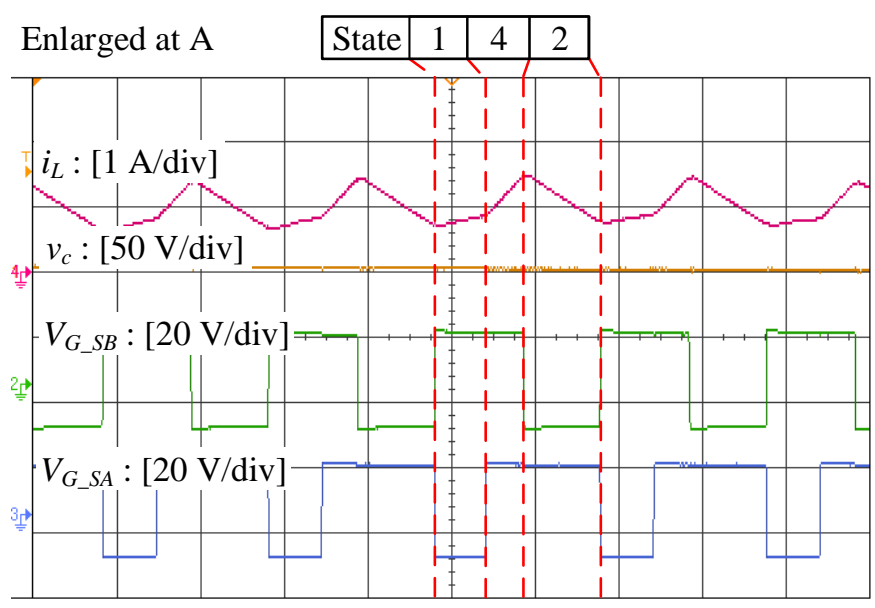

Time : $[20 \mu \mathrm{s} / \mathrm{div}]$

(a)

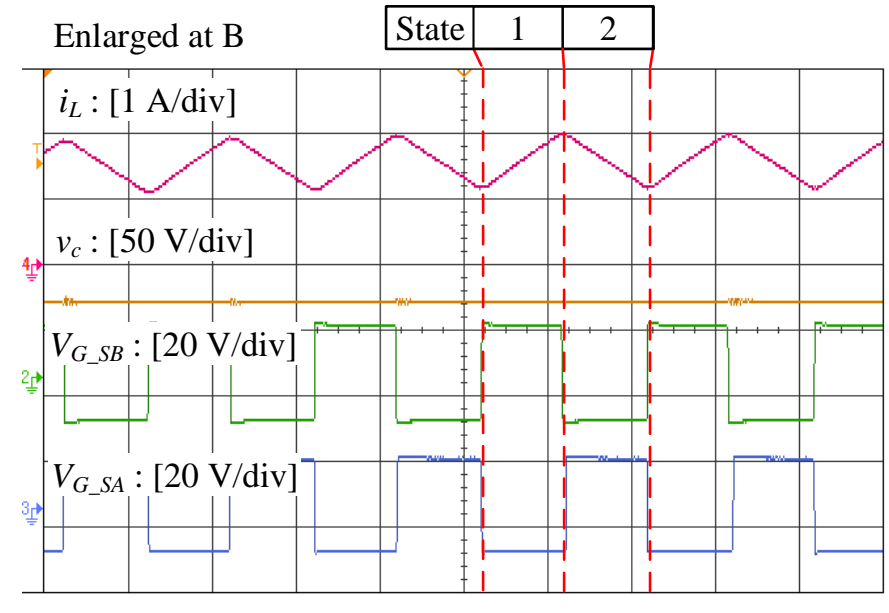

Time : $[20 \mu \mathrm{s} / \mathrm{div}]$ (b)

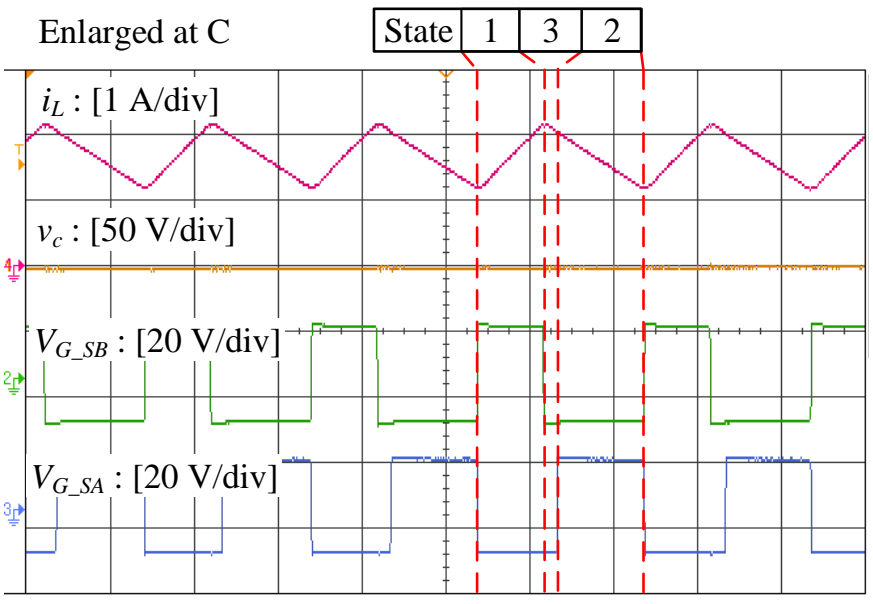

Time : $[20 \mu \mathrm{s} / \mathrm{div}]$

(c)

(d)

Fig. 15. Switching waveforms of the inductor current and capacitor voltage. (a) Overview (b) discharging phase (viewpoint A) (c) discharging-charging transition phase (viewpoint B) and (d) charging phase (viewpoint C). 
The transient response of the proposed rectifier is also examined as shown in Fig. 16. In the experiment, the output voltage is step-changed from $45 \mathrm{~V}$ to $55 \mathrm{~V}$ and then back to $45 \mathrm{~V}$. In both scenarios, there are no overshoot/undershoot in the output voltage. The system remains stable and reaches steady state within two line cycles. In addition, no significant double-line frequency ripple in $v_{o}$ is observed before, during and after the step-change interval. The ripple power (at steady state and during transient) is always diverted into $C_{S}$ automatically, even though no power decoupling loop is implemented in the control.

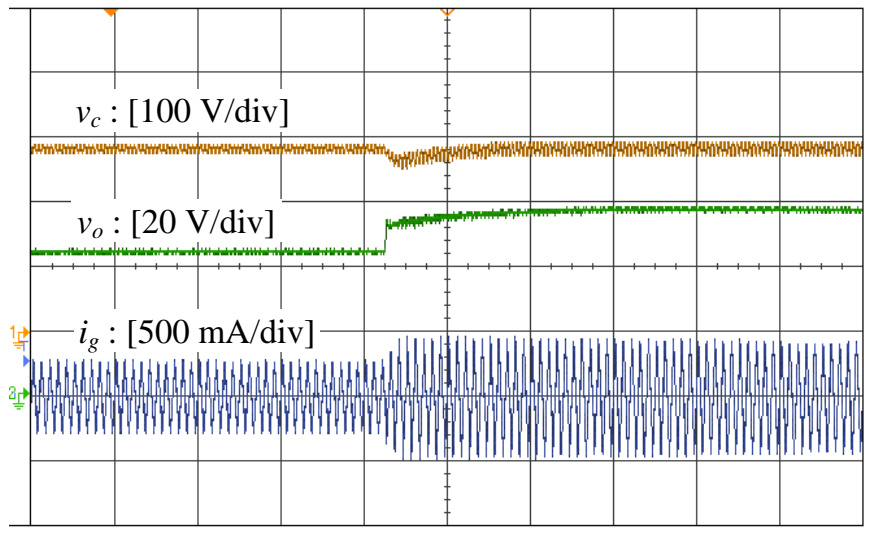

Time : [200 ms/div]

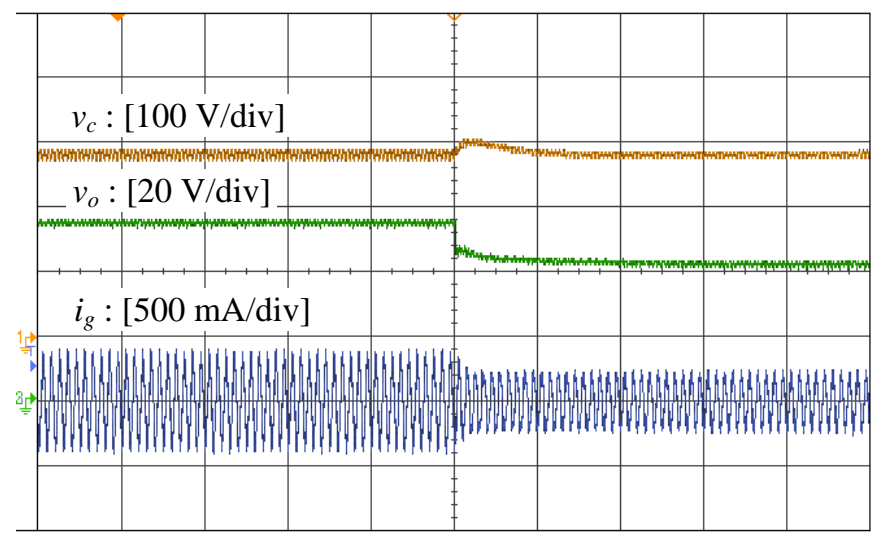

Time : [200 ms/div]

(a)

(b)

Fig. 16. Transient waveforms of the input current and the voltage of the power-buffering capacitor during a (a) step-up and (b) step-down change of the output voltage.

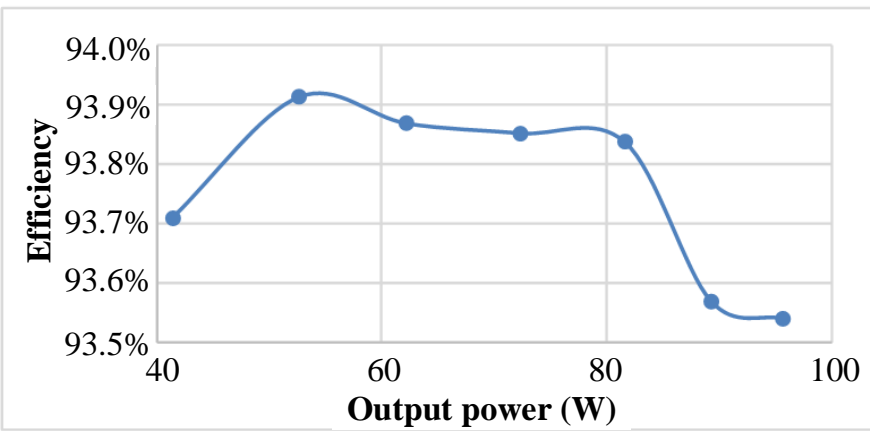

(a)

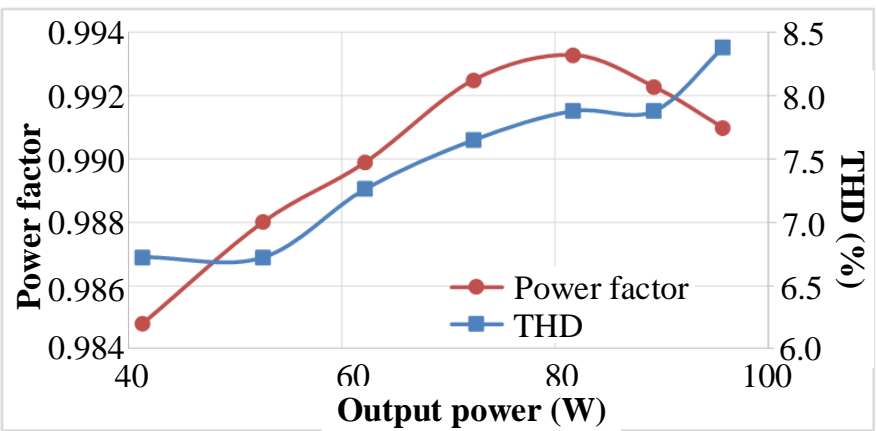

(b)

Fig. 17. (a) Measured efficiency, and (b) power and THD curves of the two-switch buck-boost PFC rectifier versus the output power. 
Fig. 17(a) shows the measured efficiency curve of the proposed rectifier within the range of $40 \%$ to $100 \%$ of rated power with the same load resistance. The peak efficiency is around $93.9 \%$ and the efficiency curve is fairly flat within the overall power ranges. Fig. 17 (b) shows the measured power factor and the input current THD versus the output power. The power factor is above 0.98 and the THD is less than $8.5 \%$. The input current harmonics in the rectifier are in compliance with the requirement of IEC 61000-3-2 (Class C).

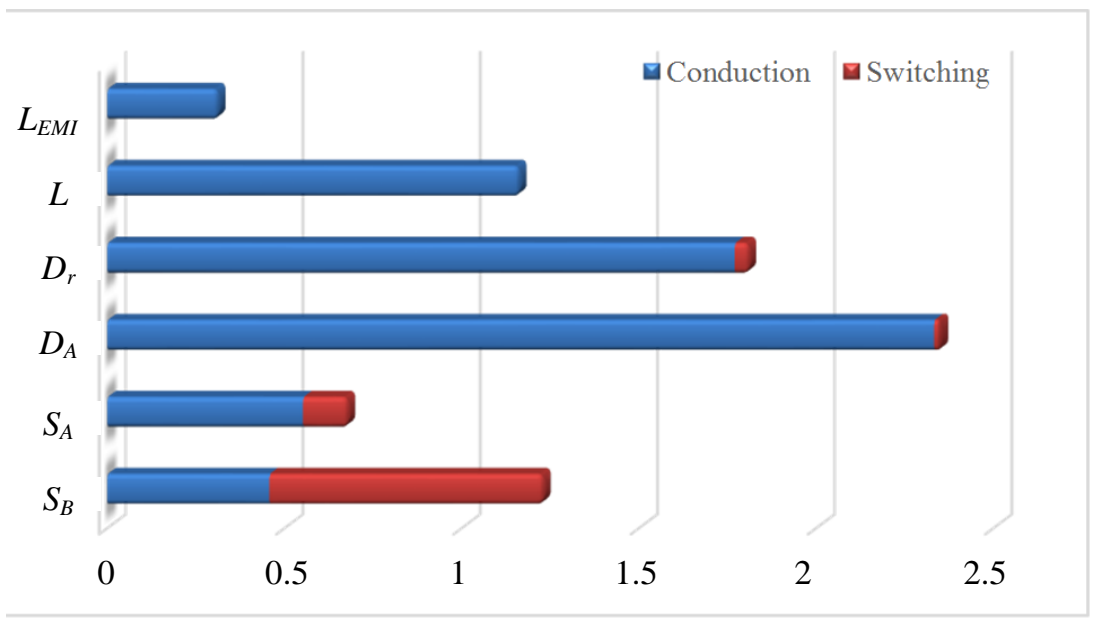

Power losses (W)

Fig. 18. Simulated power loss audit of the two-switch buck-boost PFC rectifier $\left(V_{g}=150 \mathrm{~V}, C_{S}=15 \mu \mathrm{F}, L=3 \mathrm{mH}, f_{s w}=25\right.$ $\mathrm{kHz}$ and $\left.T_{\text {line }}=20 \mathrm{~ms}\right)$.

Finally, Fig. 18 shows the power loss audit of the converter. As can be seen, the conduction loss in the diodes contributes most of the power losses. This can be explained by comparing the length of the conduction intervals of $D_{r}$ and $D_{A}$ to that of $S_{A}$ and $S_{B}$ based on Fig. 4. In addition, $S_{B}$ has a higher switching loss than that of $S_{A}$. The result is consistent with the previous analysis.

\section{CONCLUSIONS}

In this paper, a new two-switch PFC rectifier based on the concept of series power-buffer cell and the conventional buck-boost converter topology is reported. The rectifier, which comprises only two active switches, one inductor and one small power-buffering capacitor, can achieve a high power factor and good voltage regulation over a wide range of output power. In addition, an automatic power decoupling control 
scheme that is simple to implement and easy to design is proposed for this rectifier. The resulting rectifier is hence simple, cost-effective and reliable. Experimental results show that a peak efficiency of $93.9 \%$ is achievable, with a power factor of higher than 0.98 and a THD of less than $8.5 \%$. Also, a mere of $3 \%$ voltage ripple has been achieved in a $100 \mathrm{~W}$ prototype with a $15 \mu \mathrm{F}$ non-electrolytic capacitor.

\section{ACKNOWLEDGEMENT}

This work was supported by the Hong Kong Research Grant Council with the Theme-based Research Project: T23-701/14-R/N.

\section{REFERENCES}

[1] P. T. Krein, R. S. Balog, and M. Mirjafari, "Minimum energy and capacitance requirements for single-phase inverters and rectifiers using a ripple port," IEEE Trans. Power Electron., vol. 27, no. 11, pp. 4690-4698, Nov. 2012.

[2] T. Shimizu, T. Fujita, G. Kimura, and J. Hirose, "A unity power factor PWM rectifier with DC ripple compensation," IEEE Trans. Ind. Electron., vol. 44, no. 4, pp. 447-455, 1997.

[3] S. Li, S.-C. Tan, C. K. Lee, E. Waffenschmidt, S. Y. Hui, and C. Tse, "A survey, classification and critical review of lightemitting diode drivers," IEEE Trans. Power Electron., vol. PP, no. 99, pp. 1-1, 2015.

[4] R. Wang, F. Wang, D. Boroyevich, R. Burgos, R. Lai, P. Ning, and K. Rajashekara, "A high power density single-phase PWM rectifier with active ripple energy storage," IEEE Trans. Power Electron., vol. 26, no. 5, pp. 1430-1443, May 2011.

[5] H. Wang and F. Blaabjerg, "Reliability of capacitors for dc-link applications in power electronic converters-an overview," IEEE Trans. Ind. Appl., vol. 50, no. 5, pp. 3569-3578, Sep. 2014.

[6] H. Wang, H. S.-H. Chung, and L. Wenchao, "Use of a series voltage compensator for reduction of the DC-Link capacitance in a capacitor-supported system," IEEE Trans. Power Electron., vol. 29, no. 3, pp. 1163-1175, Mar. 2014.

[7] S. Wang, X. Ruan, K. Yao, S.-C. Tan, Y. Yang, and Z. Ye, "A flicker-free electrolytic capacitor-less AC-DC LED driver," IEEE Trans. Power Electron., vol. 27, no. 11, pp. 4540-4548, Nov. 2012.

[8] Y. Tang, F. Blaabjerg, P. C. Loh, C. Jin, and P. Wang, "Decoupling of fluctuating power in single-phase systems through a symmetrical half-bridge circuit," IEEE Trans. Power Electron., vol. 30, no. 4, pp. 1855-1865, Apr. 2015.

[9] M. Chen, K. K. Afridi, and D. J. Perreault, "Stacked switched capacitor energy buffer architecture," IEEE Trans. Power Electron., vol. 28, no. 11, pp. 5183-5195, Nov. 2013.

[10] T. Shimizu, Y. Jin, and G. Kimura, "DC ripple current reduction on a single-phase PWM voltage-source rectifier," IEEE Trans. Ind. Appl., vol. 36, no. 5, pp. 1419-1429, 2000.

[11]H. Li, K. Zhang, H. Zhao, S. Fan, and J. Xiong, "Active power decoupling for high-power single-phase PWM rectifiers," IEEE Trans. Power Electron., vol. 28, no. 3, pp. 1308-1319, Mar. 2013.

[12] M. Su, P. Pan, X. Long, Y. Sun, and J. Yang, "An active power-decoupling method for single-phase AC-DC converters," IEEE Trans. Ind. Informatics, vol. 10, no. 1, pp. 461-468, Feb. 2014.

[13] W. Cai, L. Jiang, B. Liu, S. Duan, and C. Zou, "A power decoupling method based on four-switch three-port DC/DC/AC converter in DC microgrid,” IEEE Trans. Ind. Appl., vol. 51, no. 1, pp. 336-343, Jan. 2015. 
[14] S. Li, G.-R. Zhu, S.-C. Tan, and S. Y. R. Hui, "Direct AC/DC rectifier with mitigated low-frequency ripple through inductorcurrent waveform control," IEEE Trans. Power Electron., vol. 30, no. 8, pp. 4336-4348, Aug. 2015.

[15] I. Serban, "Power decoupling method for single-phase H-bridge inverters with no additional power electronics," IEEE Trans. Ind. Electron., vol. 62, no. 8, pp. 4805-4813, Aug. 2015.

[16] Y. Tang and F. Blaabjerg, "A component-minimized single-phase active power decoupling circuit with reduced current stress to semiconductor switches," IEEE Trans. Power Electron., vol. 30, no. 6, pp. 2905-2910, Jun. 2015.

[17] S. Li, W. Qi, S.-C. Tan, and S. Hui, "Integration of an active-filter and a single-phase AC/DC converter with reduced capacitance requirement and component count," IEEE Trans. Power Electron., vol. PP, no. 99, pp. 1-1, 2015.

[18] Y. Ohnuma and J.-I. Itoh, "A novel single-phase buck PFC AC-DC converter with power decoupling capability using an active buffer," IEEE Trans. Ind. Appl., vol. 50, no. 3, pp. 1905-1914, May 2014.

[19] S. Funabiki, T. Tanaka, and T. Nishi, "A new buck-boost-operation-based sinusoidal inverter circuit," in 2002 IEEE 33rd Annual IEEE Power Electronics Specialists Conference. Proceedings (Cat. No.02CH37289), 2002, vol. 4, pp. 1624-1629.

[20] Y. Xue, L. Chang, S. B. Kjaer, J. Bordonau, and T. Shimizu, "Topologies of single-phase inverters for small distributed power generators: an overview," IEEE Trans. Power Electron., vol. 19, no. 5, pp. 1305-1314, Sep. 2004.

[21] R. W. Erickson and D. Maksimovic, Fundamentals of Power Electronics, 2nd ed. Springer US, 2001.

[22] International Rectifier, “Datasheet IR2101(S)/IR2102(S).” [Online]. Available: http://www.irf.com/productinfo/datasheets/data/ir2101.pdf.

[23] ON Semiconductor, "Schematic for the NCP1606BOOST Evaluation Board," $2007 . \quad[$ Online]. Available: http://www.onsemi.com/pub_link/Collateral/NCP1606BOOSTGEVB_SCHEMATIC.PDF. 